\title{
Methods for teaching evidence-based practice: a scoping review
}

\author{
Camilla Marie Larsen ${ }^{1,2,4^{*}}$ (D), Anne Seneca Terkelsen ${ }^{1}$, Anne-Marie Fiala Carlsen ${ }^{3}$ (D) and Hanne Kaae Kristensen ${ }^{1,5}$ (D)
}

\begin{abstract}
Background: This scoping review aims to gather and map inspiration, ideas and recommendations for teaching evidence-based practice across Professional Bachelor Degree healthcare programmes by mapping literature describing evidence-based practice teaching methods for undergraduate healthcare students including the steps suggested by the Sicily Statement.

Methods: A computer-assisted literature search using PubMed, Cinahl, PsycINFO, and OpenGrey covering health, education and grey literature was performed. Literature published before 2010 was excluded. Students should be attending either a Professional Bachelor's degree or a Bachelor's degree programme. Full-text articles were screened by pairs of reviewers and data extracted regarding: study characteristics and key methods of teaching evidence-based practice. Study characteristics were described narratively. Thematic analysis identified key methods for teaching evidencebased practice, while full-text revisions identified the use of the Sicily Statement's five steps and context.

Results: The database search identified 2220 records. One hundred ninety-two records were eligible for full-text assessment and 81 studies were included. Studies were conducted from 2010 to 2018. Approximately half of the studies were undertaken in the USA. Study designs were primarily qualitative and participants mainly nursing students. Seven key methods for teaching evidence-based practice were identified. Research courses and workshops, Collaboration with clinical practice and IT technology were the key methods most frequently identified. Journal clubs and Embedded librarians were referred to the least. The majority of the methods included 2-4 of the Sicily Statement's five steps, while few methods referred to all five steps.

Conclusions: This scoping review has provided an extensive overview of literature describing methods for teaching EBP regarding undergraduate healthcare students. The two key methods Research courses and workshops and Collaboration with clinical practice are advantageous methods for teaching undergraduate healthcare students evidence-based practice; incorporating many of the Sicily Statement's five steps. Unlike the Research courses and workshop methods, the last step of evaluation is carried out partly or entirely in a clinical context. Journal clubs and Embedded librarians should be further investigated as methods to reinforce existing methods of teaching. Future research should focus on methods for teaching EBP that incorporate as many of the five steps of teaching and conducting EBP as possible.
\end{abstract}

Keywords: Teaching methods, Undergraduate healthcare students, Evidence-based practice, The Sicily statement

\section{Background}

Dizon et al. state that healthcare can be inefficient, ineffective and/or dangerous when it is not based on current best evidence [1,2]. Therefore, to ensure the quality of healthcare, it is important to implement evidence-based

\footnotetext{
*Correspondence: cmla2@ucl.dk; cmla@ucl.dk

${ }^{1}$ Health Sciences Research Centre, UCL University College, Niels Bohrs Allé 1 , 5230 Odense M, Denmark

${ }^{2}$ Department of Physiotherapy, UCL University College, Niels Bohrs Allé 1,

5230 Odense M, Denmark

Full list of author information is available at the end of the article
}

practice (EBP) in all health professional curricula, so that future health professionals learn the fundamentals of research and the application of evidence in practice [2].

Several definitions of EBP have been suggested in recent years. The scientific evidence was initially developed within medicine, but as many health professionals have embraced an evidence-based way of practice the Sicily Statement [3] suggested that the original term "evidencebased medicine" should be expanded to "evidence-based

(c) The Author(s). 2019 Open Access This article is distributed under the terms of the Creative Commons Attribution 4.0 International License (http://creativecommons.org/licenses/by/4.0/), which permits unrestricted use, distribution, and reproduction in any medium, provided you give appropriate credit to the original author(s) and the source, provide a link to the Creative Commons license, and indicate if changes were made. The Creative Commons Public Domain Dedication waiver (http://creativecommons.org/publicdomain/zero/1.0/) applies to the data made available in this article, unless otherwise stated. 
practice" in order to reflect a common approach to EBP across all health professions.

The Sicily Statement gives a clear definition of EBP together with a description of the minimum level of educational requirements and skills required to practice in an evidence-based manner. This makes the underlying processes of EBP more transparent and distinguishes between the process and outcome of EBP [3].

In order to fulfil the minimum requirements of teaching and conducting EBP, the Sicily Statement puts forward a five-step model: (I) asking a clinical question; (II) collecting the most relevant evidence; (III) critically appraising the evidence; (IV) integrating the evidence with one's clinical expertise, patient preferences and values to make a practice decision; and $(\mathrm{V})$ evaluating the change or outcome [4].

Internationally, EBP skills are essential requirements in clinical practice among both medical doctors as well as among other health professionals. Healthcare students are mainly taught the first three steps of the Sicily Statement's five-step model. The last two steps are rarely taught, and students and graduates thus lack competencies in applying their knowledge in the clinical setting during or after graduation $[5,6]$.

In terms of healthcare policy and ambitions in Denmark, it was decided in 2015 that Professional Bachelor Degree healthcare students were to contribute to the development of an evidence-based way of working, a faster implementation of new knowledge in practice, and to the development of greater patient involvement and patient safety in the $\mathrm{Da}$ nish healthcare system [7]. The Professional Bachelor's degree is awarded after 180-270 ECTS and includes a period of work placement of at least 30 ECTS. The programmes are applied programmes. They are development-based and combine theoretical studies with a practical approach. Examples of professional bachelor degree holders are nurses. The Danish title is Professionsbachelor and the English title is Bachelor [8]. In Denmark the University College institutions solely provide professional bachelor degree educations. Master degrees are awarded at the Universities.

Based on the Sicily Statement students should be able to reflect, ask questions, gather knowledge, critically appraise, apply and evaluate various kinds of knowledge at the end of their course. The aim is that all Professional Bachelor Degree healthcare students across disciplines of nursing, physiotherapy, occupational therapy, radiography, and biomedical laboratory science develop common EBP qualifications in order to contribute towards the development of evidence-based healthcare [9]. In order to ensure shared prerequisites and mutual understanding of the EBP concepts before entering theoretical or clinical interprofessional education, further knowledge about how to teach EBP across disciplines is required [9]. By teaching the fundamental principles of EBP, students will develop their EBP skills and ability to put them into practice in their studies and as future graduates.

Previously, some systematic reviews were conducted summarising various educational interventions or strategies for teaching EBP to undergraduate healthcare students [2, 10-12].

In a review from 2014, Young and colleagues stated that multifaceted interventions integrated into clinical practice contributed to the greatest improvements in EBP knowledge, skills, and attitudes [2]. In line with this, Kyriakoulis et al. suggested that a combination of interventions, such as lectures, tutorials, workshops, conferences, journal clubs, and online sessions was best suited for teaching EBP to undergraduate healthcare students [10]. However, the majority of the articles in both reviews synthesized information from interventions or strategies aimed at medical students at various educational levels. Only a few articles elicited information about educational interventions and strategies aimed at undergraduate healthcare students in the disciplines of nursing, physiotherapy, occupational therapy, radiography, and/or biomedical laboratory science. However, two recent reviews have specifically addressed EBP teaching for undergraduate nursing students [11, 12]. A systematic review investigated the effectiveness of specific educational methods and found an effect on student knowledge, attitudes, and skills but could not draw a conclusion as to the advisability of one of the methods [11]. A literature review sought to identify knowledge experiences on teaching strategies from qualitative studies in nursing EBP education to enhance knowledge and skills and points to a limited focus on the use of EBP teaching strategies. Additionally, the study points to the need for more qualitative research investigating interactive and clinically integrated teaching strategies. Despite both reviews being well-informing, a broad scope when mapping updated EBP teaching methods and strategies across healthcare bachelor educations will further qualify future interdisciplinary practices [11, 12].

In order to implement the most effective ways of teaching EBP across healthcare undergraduate students, an investigation of existing literature on the subject needs to be undertaken. For identifying, mapping and discussing key characteristics in the literature a scoping review is the better choice [13].

\section{Aim, objectives and review question}

The aim of this scoping review is to gather and map inspiration, ideas, and recommendations for teachers implementing EBP across Professional Bachelor Degree healthcare programmes by mapping existing literature describing EBP teaching methods, including the five steps of EBP suggested by the Sicily Statement, [3] regarding undergraduate healthcare students. 
The primary question of the scoping review is: "Which EBP teaching methods, including The Sicily Statement's steps of teaching and conducting EBP, have been reported in the literature with respect to undergraduate healthcare students in classrooms and clinical practice?"

\section{Definitions}

Classroom is defined as a room where classes are taught in a school, college or university [14].

Clinical practice refers to the agreed-upon and customary means of delivering healthcare by doctors, nurses and other health professionals [15].

\section{Methods}

To ensure a systematic methodology, The Joanna Briggs Institute Reviewers' Manual - Methodology for JBI Scoping Reviews has been used throughout the scoping review process $[16,17]$.

\section{Inclusion criteria Participants}

Literature which included undergraduate healthcare students in the disciplines of nursing, physiotherapy, occupational therapy, radiography, and biomedical laboratory science was selected to ensure applicability and relevance to similar scientific disciplines at other institutions of higher education. The undergraduate students should be attending either a Professional Bachelor's degree or a Bachelor's degree programme.

\section{Concept}

Methods for teaching EBP including The Sicily Statement's steps of teaching and conducting EBP was the main concept to be investigated in the review. That is; literature describing either recommendations of EBP teaching methods, evaluations of EBP teaching methods, teacher and/or student perceptions of EBP teaching and learning methods, or qualifications obtained when learning the principles of EBP.

\section{Context}

Literature describing methods for teaching EBP conducted in a classroom setting, in clinical practice as part of the education, or in a combination of classroom and clinical practice was included in the review.

\section{Exclusion criteria}

In the period up to 2010, the Bachelor Degree healthcare educations began to conform to European requirements regarding evidence-informed and evidence-based education [18].

A maximum time frame (2010-2018) was applied, determined by the amount of available literature/research studies and requirements of updated teaching strategies $[19,20]$. Therefore, literature published before 2010 was excluded.
Literature including undergraduate students in other health disciplines such as medicine or dentistry was not reviewed as the structure of their education is based on another paradigm. Nor was literature including participants such as graduates, RN-to-BSN students, and trained health personnel accepted for inclusion as they were considered as postgraduates, not comparable to undergraduate students. With the primary aim of gathering ideas and inspiration for teaching EBP, literature that focused on issues other than methods for teaching EBP was excluded, as well as literature in languages other than English, Danish, Norwegian, or Swedish.

\section{Search strategy}

To identify literature relevant to our research question, the databases MEDLINE via PubMed, CINAHL Complete, and PsycINFO (both via EBSCO) were systematically searched. These databases cover both health and education and are available to the primary local target audience of this scoping review. Because of time limitations only the multidisciplinary European database, OpenGrey, was searched in the attempt to find unpublished literature. The searches were conducted May 9th, 2018.

As recommended in The Joanna Briggs Institute Reviewers' Manual [16, 17], the search was conducted in three steps in collaboration with a research librarian.

Step 1: The databases PubMed, covering the field of biomedicine and CINAHL, covering nursing and allied health literature were searched using the keywords: 'teaching methods,' 'teaching,' 'learning methods,' 'learning,' 'teaching strategies,' 'learning strategies,' 'undergraduate,' 'undergraduate education,' student,' 'biomedical laboratory scientist,' 'medical laboratory scientist,' 'medical laboratory technologist,' 'medical laboratory technologists', 'radiographer,',occupational therapist,' 'physiotherapist', 'nurse', and 'evidence-based practice'.

Step 2: Through an analysis of text words in titles and abstracts of the studies found in PubMed and Cinahl, new keywords, which would improve the search, were identified. These were 'allied health', health students', and 'nursing'. All identified keywords were then included in the search as a systematic block search in PubMed, Cinahl, and PsycINFO, covering literature in the behavioural and social sciences, and OpenGrey, covering grey literature in Europe. Table 1 provides a list of the specific search queries used in all databases. Step 3: The reference lists of identified studies were searched for additional studies.

\section{Study selection}

All search results from the databases were imported to the web-based bibliographic management software, RefWorks 2017 by ProQuest. After exclusion of duplicates and 
records before 01.01.2010, two reviewers independently screened titles and abstracts of the remaining articles for relevance in relation to the research question and the inclusion and exclusion criteria. Afterwards, all full-text articles were further checked for relevance by two independent reviewers. Any inconsistencies between the two reviewers regarding study selection for final inclusion were resolved by discussion with a third reviewer.

\section{Data collection}

Data from the included articles were extracted using two data extraction tools as recommended in The Joanna Briggs Institute Reviewers' Manual [16, 17]. The first data extraction tool comprised study characteristics, while the other data extraction tool comprised methods for teaching EBP.

Prior to the process of extracting data from the included articles, a pilot test using the data extraction tools was conducted by one reviewer assessing nine articles. To ensure agreement between reviewers, a second reviewer checked the same articles. Any disagreements about the content or use of the data extraction tools were discussed and resolved.

One reviewer then extracted relevant data from all included articles to the data extraction tools. Two other reviewers split the same articles among them and extracted data using the same data extraction tools. As a final step, the first reviewer went through all extracted data from all of the included articles with each of the other reviewers to ensure comparability and completeness in the final data extraction tools.

\section{Synthesis and analysis of results}

The data extraction tools formed the basis of the final presentation of the results in two tables consisting of "Study characteristics" and "Key methods for teaching EBP, the Sicily Statement's five steps of teaching and conducting EBP and context". Study characteristics included author, year of publication, title, journal, country of origin, study design, study participants, methods for teaching EBP, and main study findings. The key methods for teaching EBP were identified through a thematic analysis. All full text articles were read and every teaching method found was listed. Through a revision of all teaching methods listed, seven themes were found that described the most prominent teaching methods, which were named "Key methods for teaching EBP". All methods were then divided into one of the key methods for teaching EBP. In some articles, more than one teaching method was described. In that case, the teaching method most frequently described was selected and categorised under the relevant key method. Through full-text revision the Sicily Statement's steps of teaching and conducting EBP and the context (classroom, clinical practice or a combination of both) in which the teaching took place was found. To further clarify the content of the two tables all results listed were described narratively. All tabulated data, except for the key methods for teaching EBP identified in Table 3, have been cited directly from the articles.

\section{Results \\ Literature search}

The database search returned 2220 records: PubMed $(n=1469)$, Cinahl $(n=527)$, PsycINFO $(n=173)$, and OpenGrey $(n=51)$ (Fig. 1). Records published before 01.01.2010 and duplicates were removed, which left 1280 records to be screened by title and abstract. Based on relevance, 1088 records were excluded and 192 records were found eligible for full-text assessment. In accordance with the inclusion and exclusion criteria, 111 articles were excluded. The excluded articles concerned study participants other than undergraduate healthcare students (graduates, RN-to-BSN students, trained health personnel), study participants from other healthcare disciplines (medicine, dentistry, midwifery), issues other than methods for teaching EBP (simulation teaching, community health nursing, EBP beliefs, etc.), and full-text articles not available in English, Danish, Norwegian, and Swedish (French, Chinese). In agreement with the other reviewers, 81 studies were finally included in the scoping review.

Table 1 Specific search queries, all databases

\begin{tabular}{|c|c|}
\hline Database & Search queries \\
\hline PubMed & $\begin{array}{l}((((\text { teaching OR learning }))) \text { AND (undergraduate OR student OR allied health OR health students)) AND ((biomedical laboratory } \\
\text { scientist OR medical laboratory scientist OR medical laboratory technologist OR medical laboratory technologists OR radiographer } \\
\text { OR occupational therapist OR physiotherapist OR nurse OR nursing))) AND evidence-based practice }\end{array}$ \\
\hline Cinahl Complete & $\begin{array}{l}\text { (teaching OR learning) AND (undergraduate OR student OR allied health) AND (biomedical laboratory scientist OR medical } \\
\text { laboratory scientist OR medical laboratory technologist OR medical laboratory technologists OR radiographer OR occupational } \\
\text { therapist OR physiotherapist OR nurse OR nursing) AND evidence-based practice }\end{array}$ \\
\hline $\begin{array}{l}\text { Psyclnfo via } \\
\text { EBSCO }\end{array}$ & $\begin{array}{l}\text { (teaching OR learning) AND (undergraduate OR student OR allied health) AND (biomedical laboratory scientist OR medical } \\
\text { laboratory scientist OR medical laboratory technologist OR medical laboratory technologists OR radiographer OR occupational } \\
\text { therapist OR physiotherapist OR nurse OR nursing) AND evidence-based practice }\end{array}$ \\
\hline Open Grey & $\begin{array}{l}\text { ("Evidence based practice" OR EBP OR Evidence-based practice OR Evidence based practice) AND (teaching OR education OR learn- } \\
\text { ing) AND (undergraduate OR student OR students) }\end{array}$ \\
\hline
\end{tabular}




\section{Study characteristics}

Study characteristics are presented in Table 2. All studies were spread across the years 2010-2018. Almost half of the studies $(n=40)$ were conducted in the USA, followed by Canada $(n=8)$, Norway $(n=$ 7), Australia $(n=6)$, England $(n=6)$, Sweden $(n=$ $3)$, China $(n=2)$, Finland $(n=2)$, Spain $(n=2)$, Greece $(n=1)$, Iran $(n=1)$, Lebanon $(n=1)$, Scotland $(n=1)$, and Taiwan $(n=1)$. The study designs were primarily qualitative $(n=55)$, while 23 of the studies were quantitative, and three of the studies used a mixed method. The majority of the participants were nursing students $(n=72)$, followed by a combination of nursing students and students from other healthcare disciplines $(n=5)$, nursing and physiotherapy students $(n=1)$, physiotherapy students and students from other healthcare disciplines $(n=1)$, occupational and physiotherapy students $(n=1)$, and physiotherapy students only $(n=1)$.
Key methods for teaching EBP, the Sicily Statement's five steps of teaching and conducting EBP and context

Table 3 presents the key methods for teaching EBP, the Sicily Statement's five steps of teaching and conducting EBP, and the context. Seven key methods for teaching EBP were identified: Thirty-two studies described "Research courses and workshops". "Collaboration with clinical practice" was identified 14 times followed by "IT technology" $(n=8)$, "Assignments" $(n=5)$, "Participation in research projects" $(n=5)$, "Journal clubs" $(n=2)$, and "Embedded librarians" $(n=2)$. In addition, 13 studies described various theories of teaching and learning. These are not elaborated on as the theme is not considered within the objective of this scoping review.

In Table 3 the vast majority of the studies $(n=69)$ referred to one or more of the Sicily Statement's five steps of teaching and conducting EBP. Eleven studies referred to all five steps. Thirty-one studies referred to three or four steps, while 17 studies referred to two of the steps,

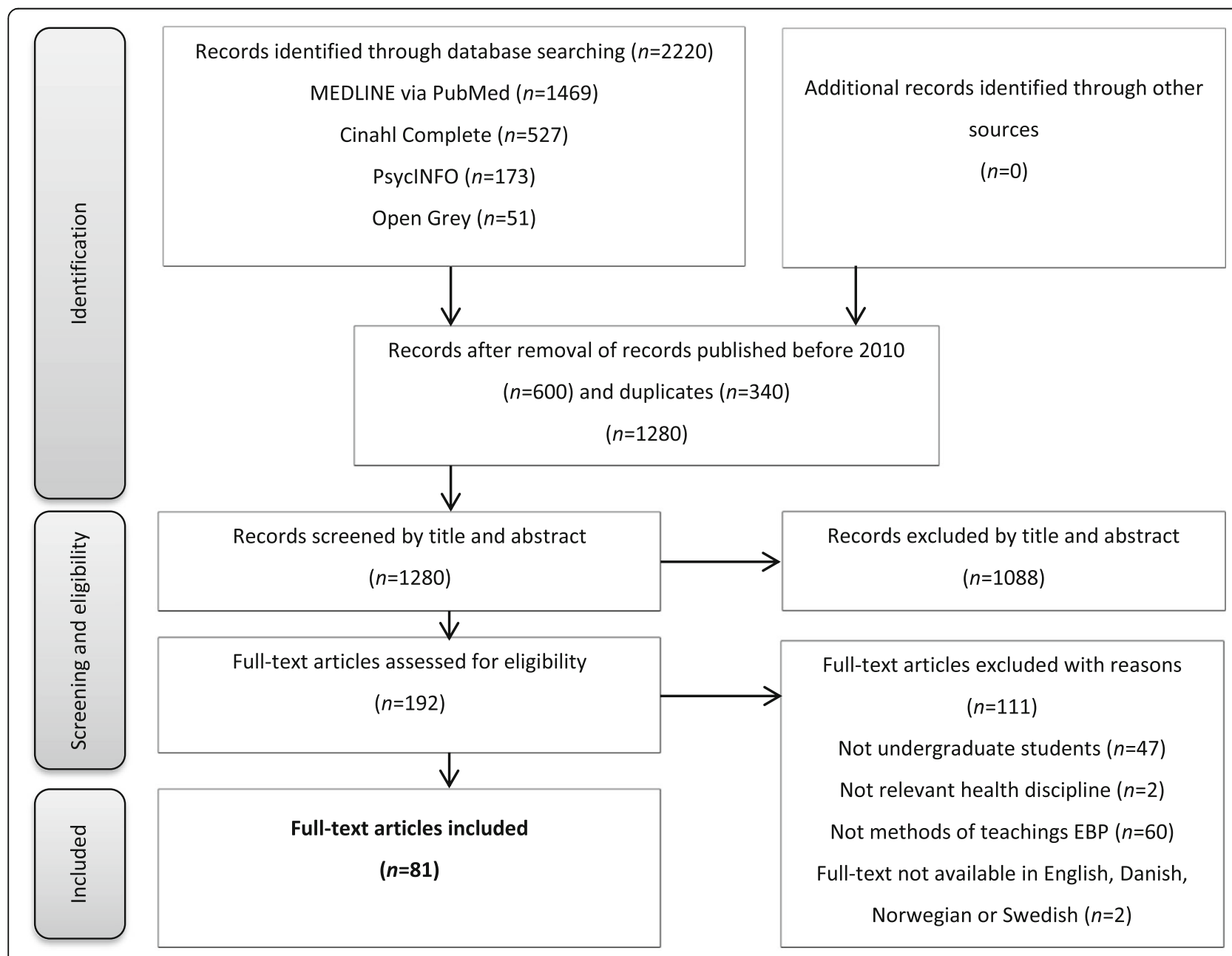

Fig. 1 Modified PRISMA flow diagram illustrating the scoping review selection process 


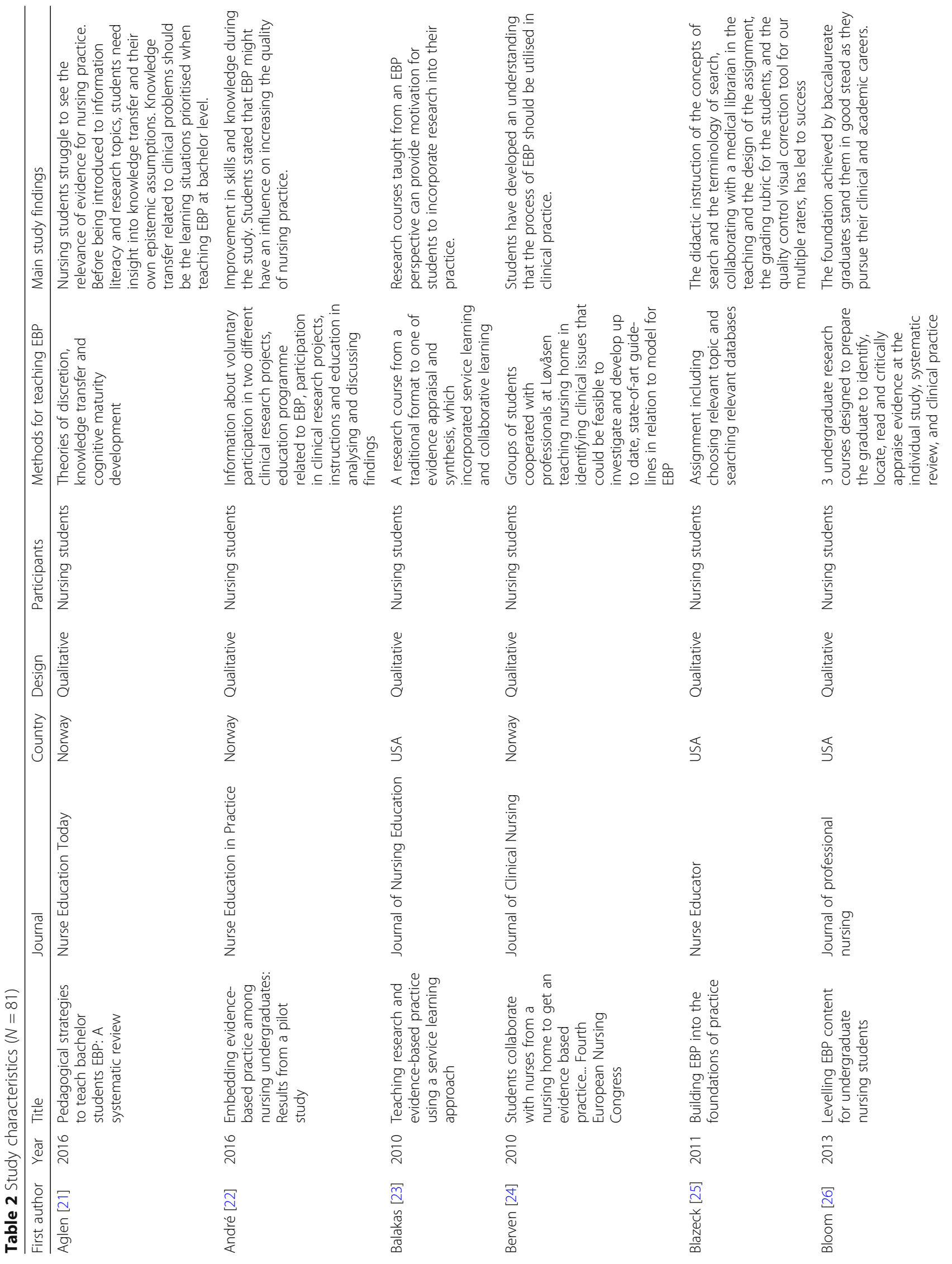




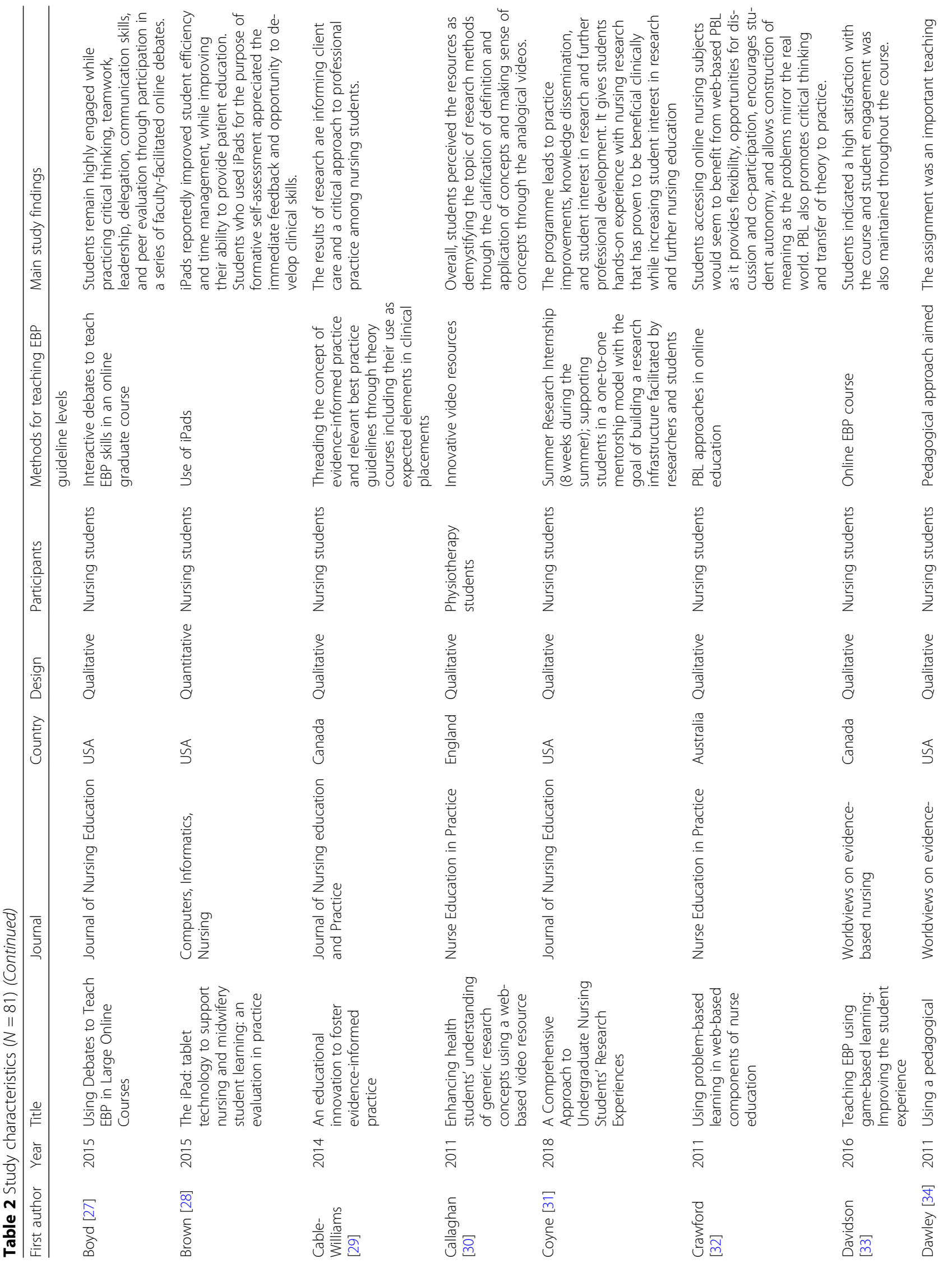




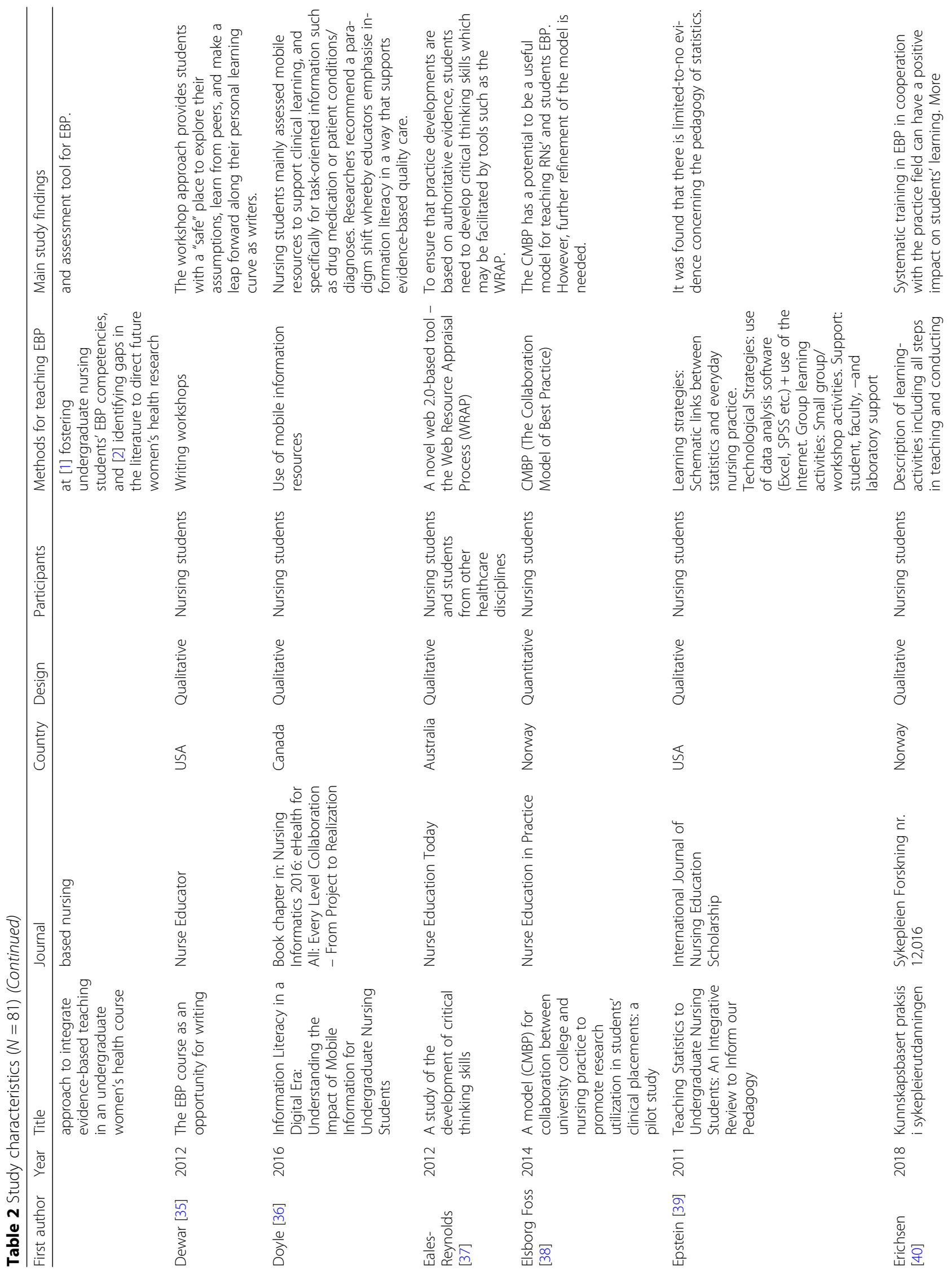




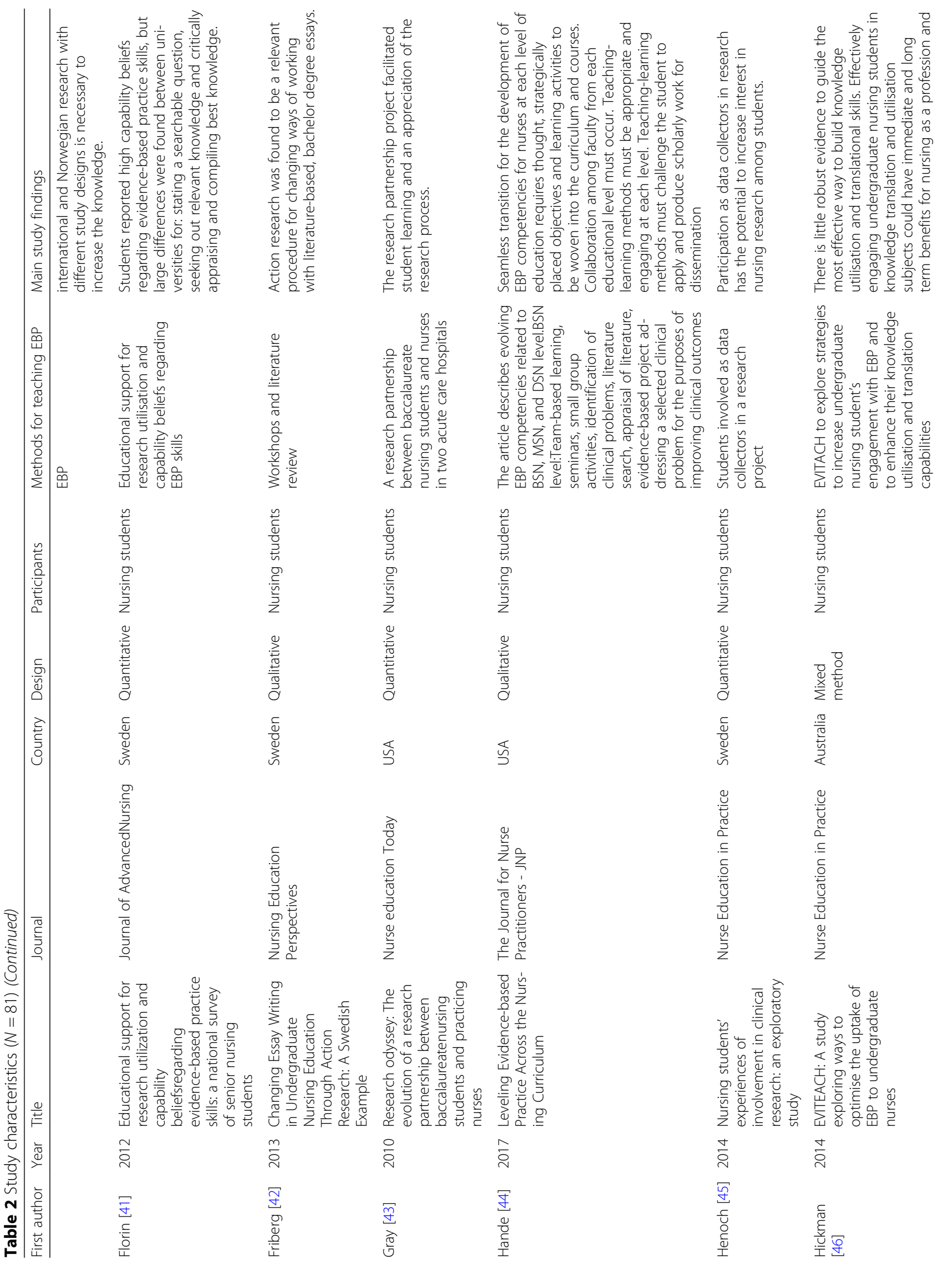




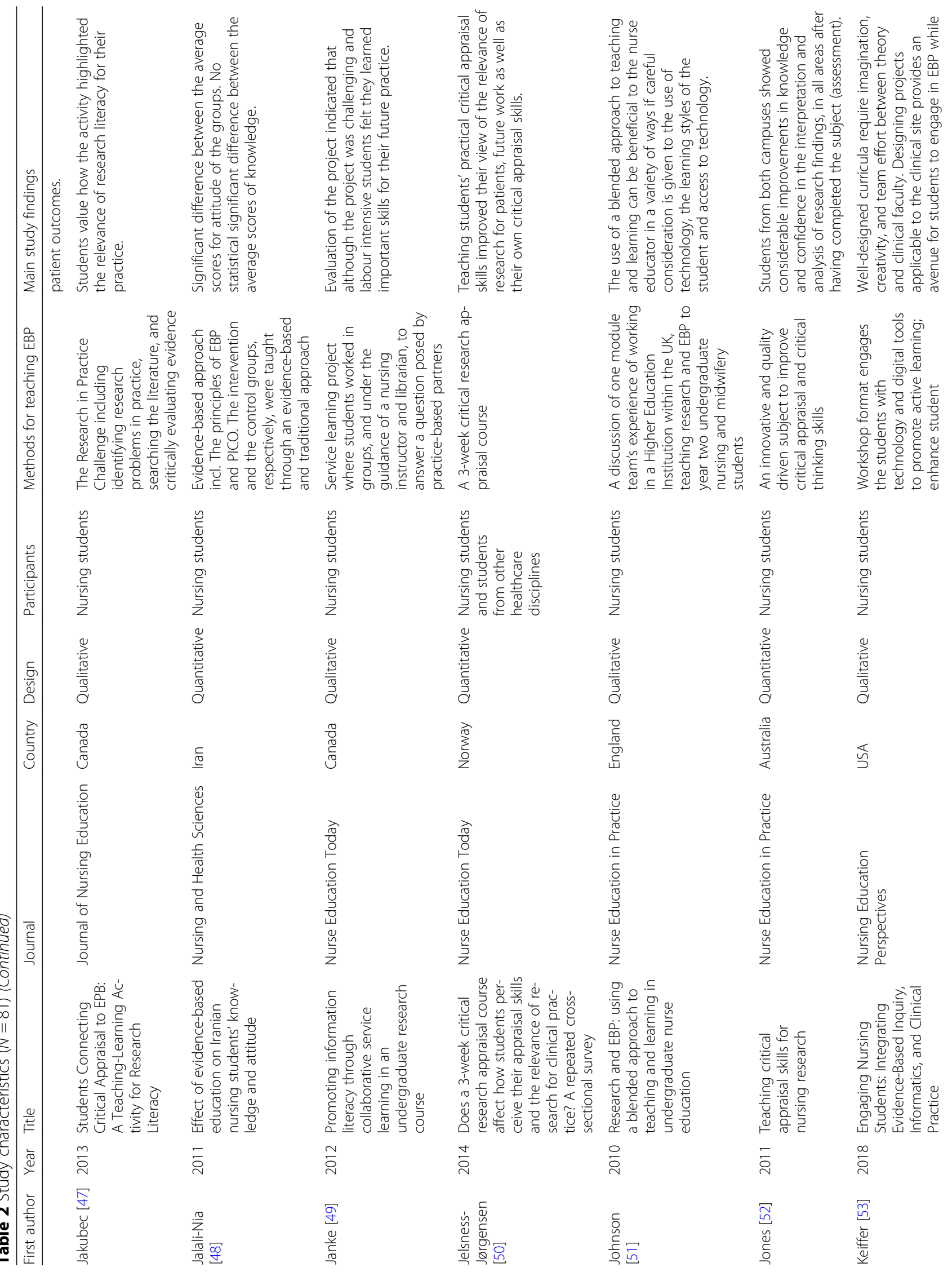




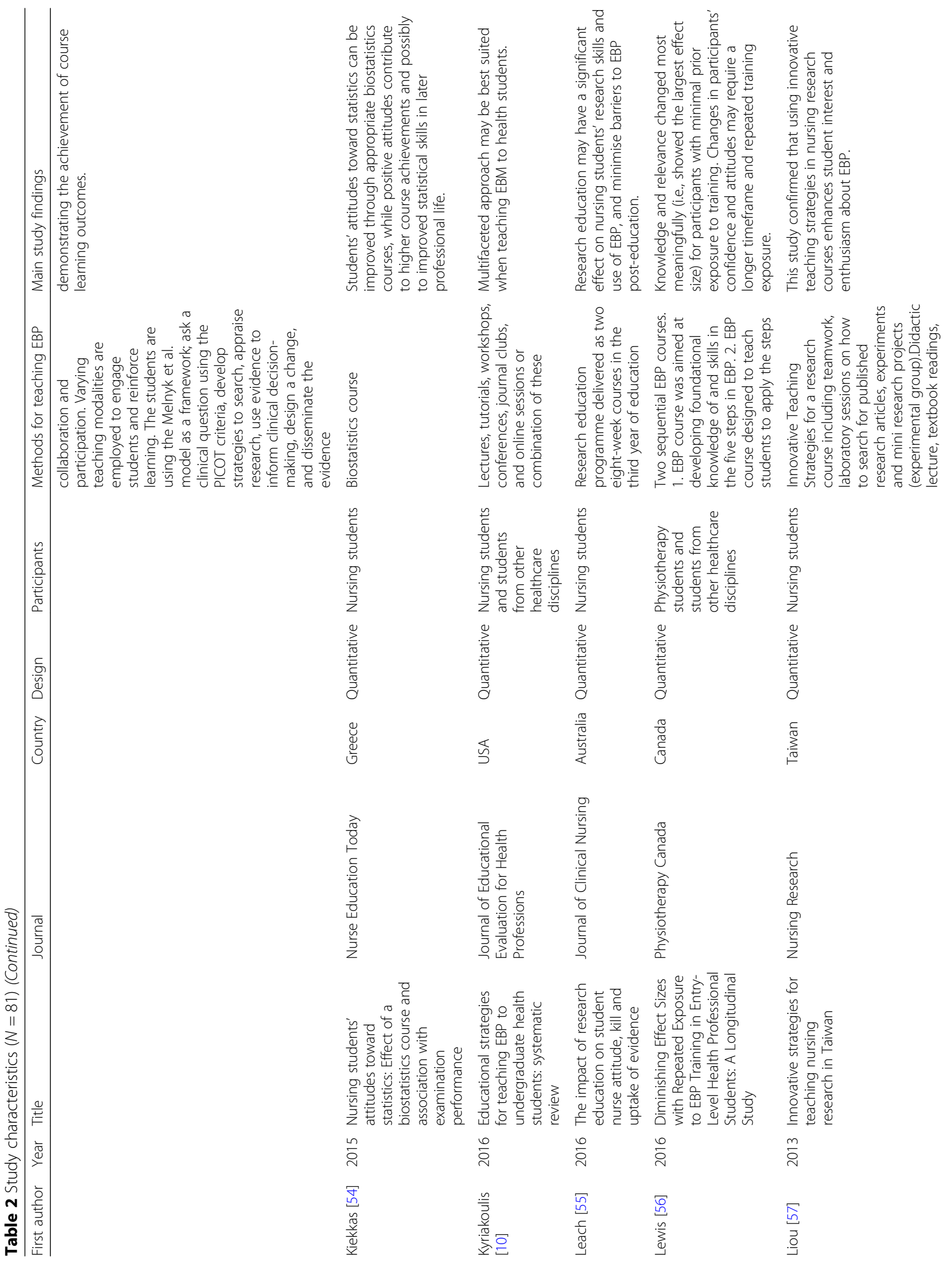




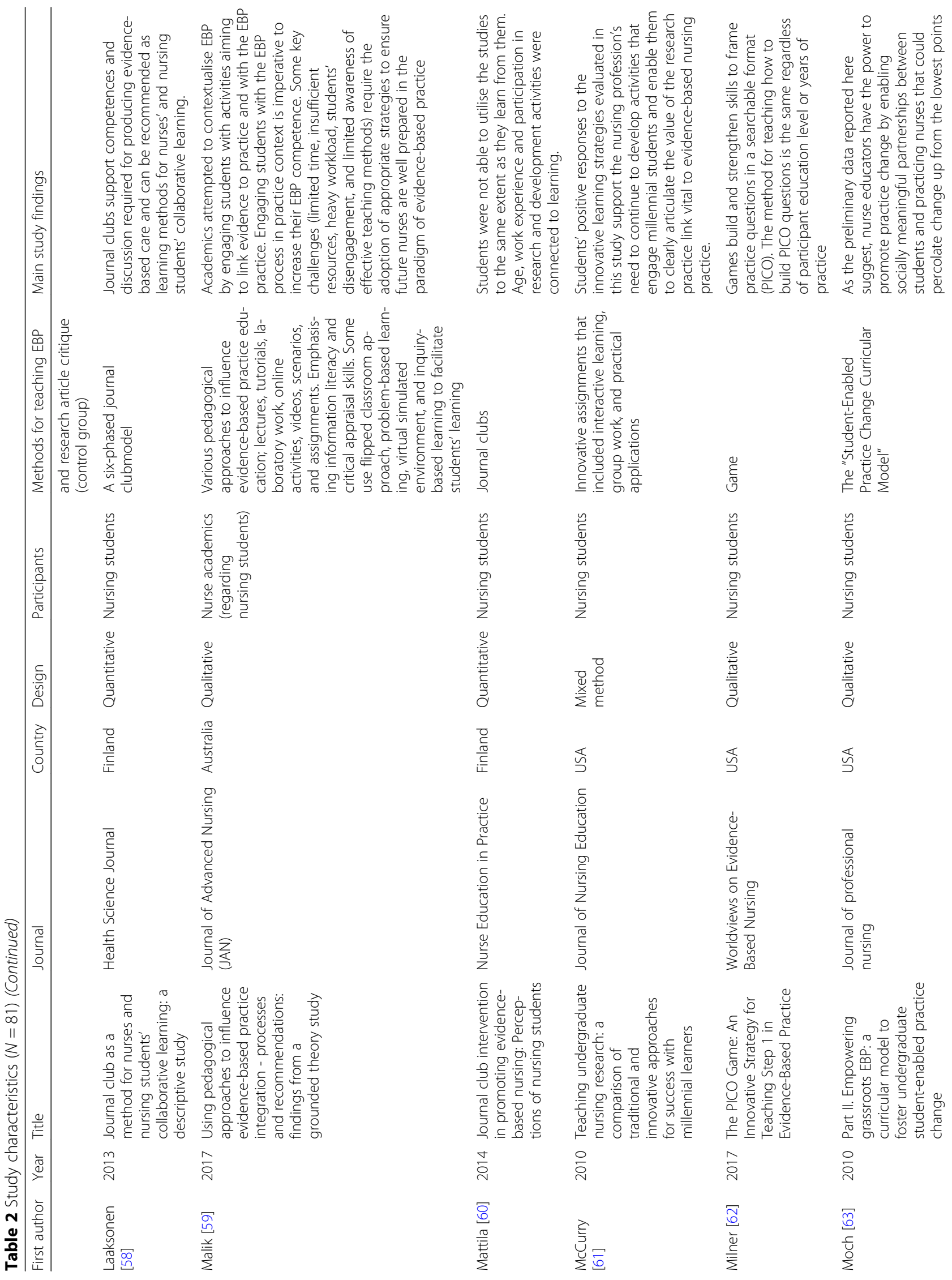




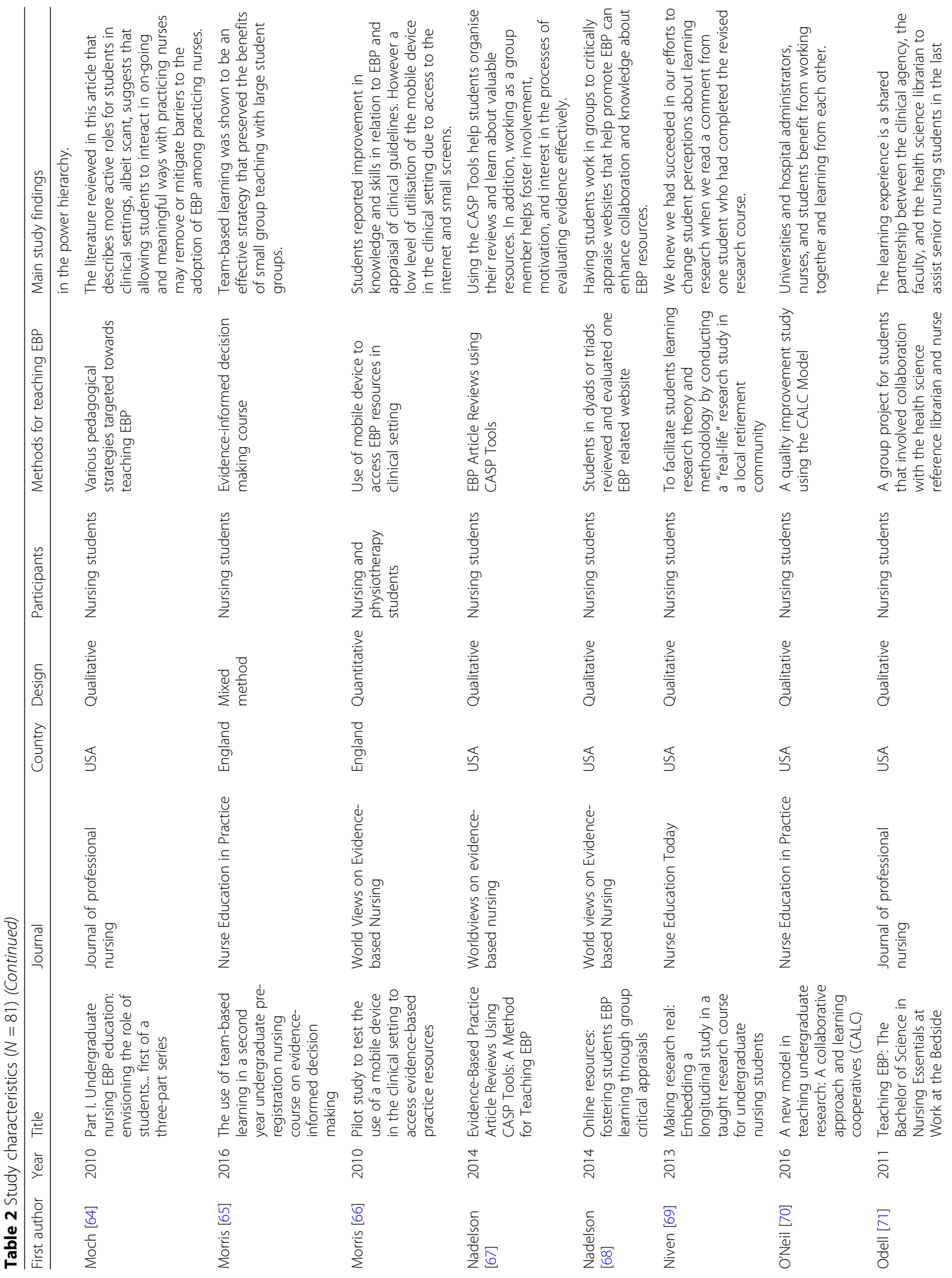




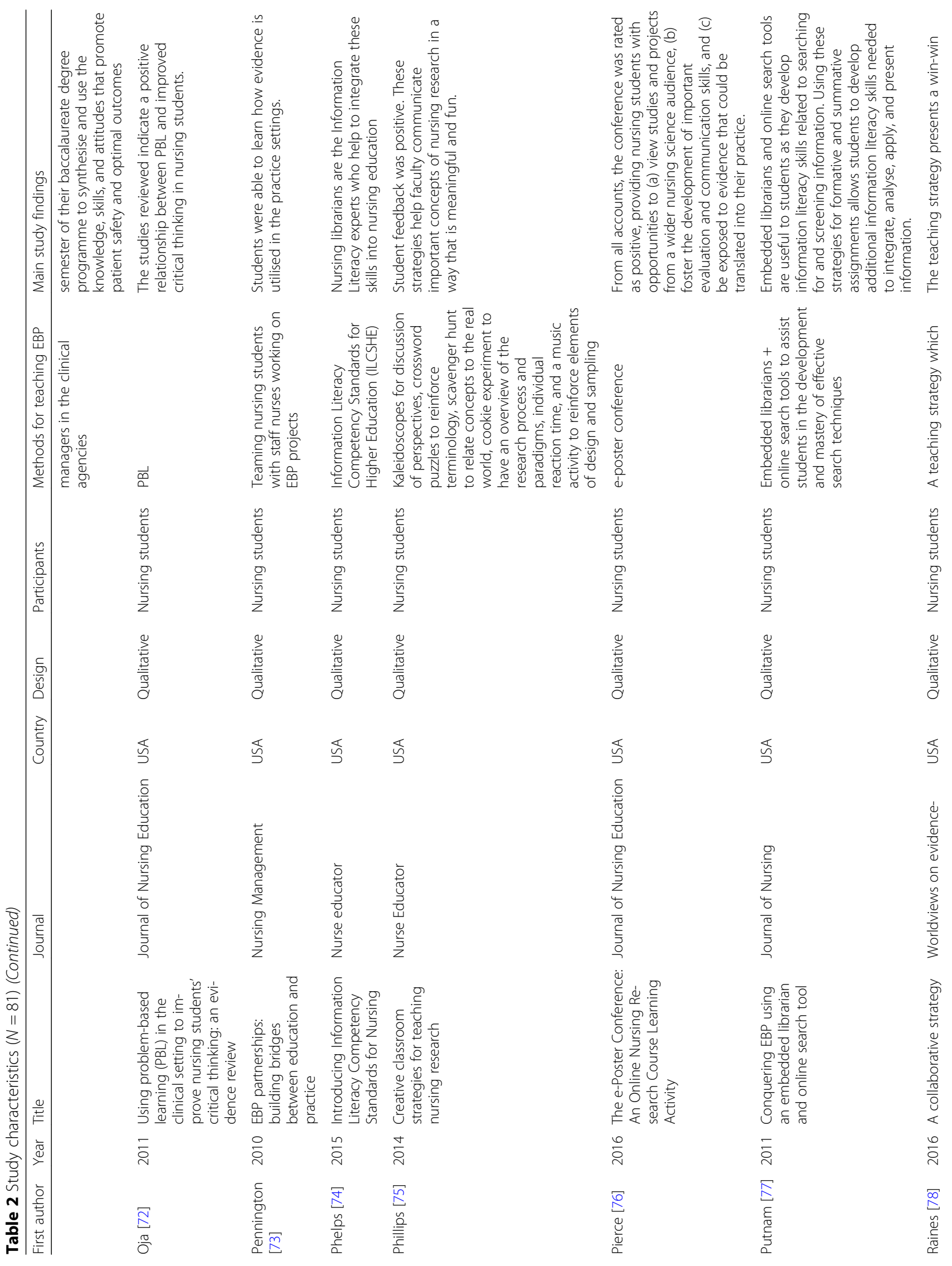




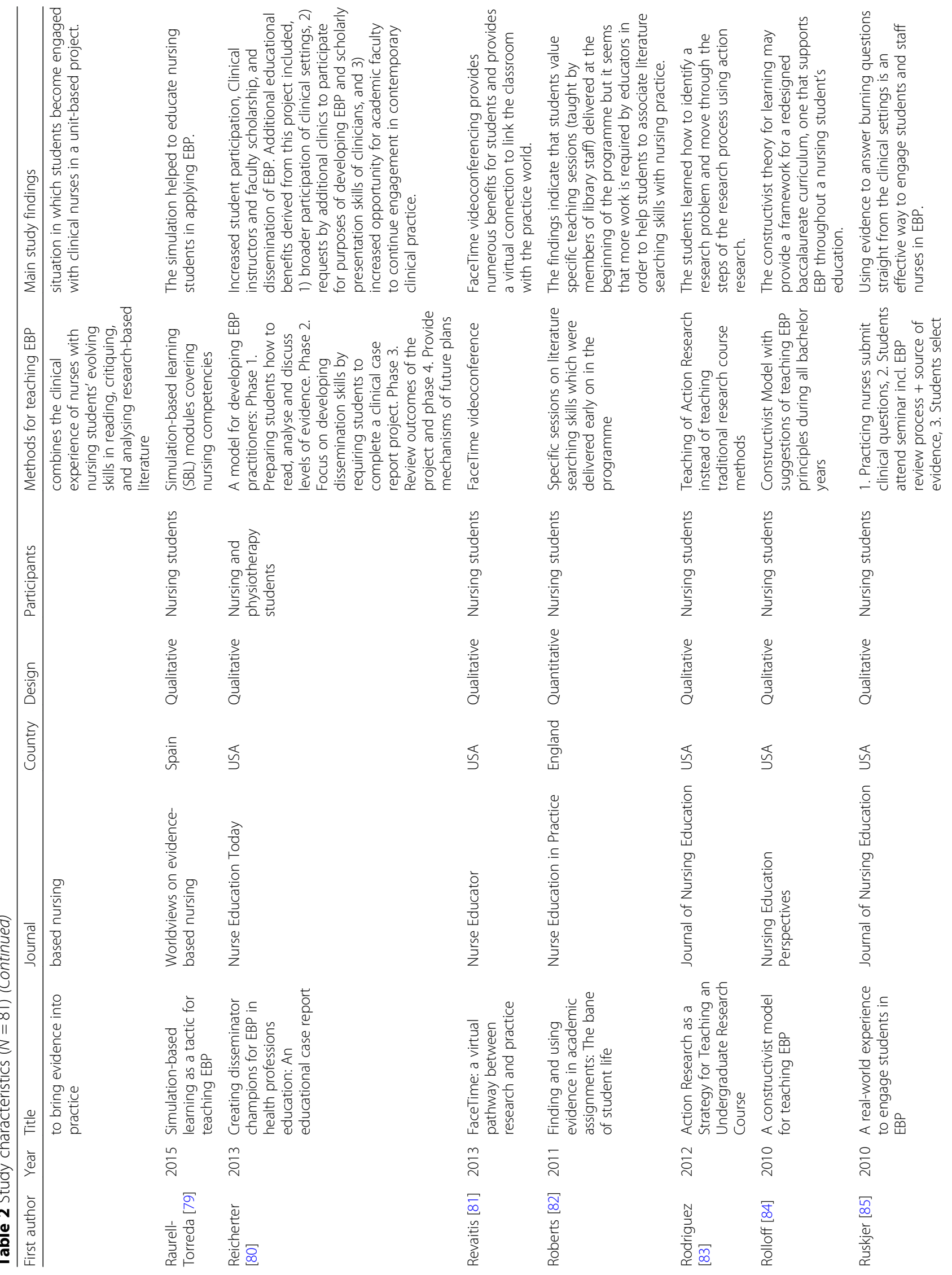




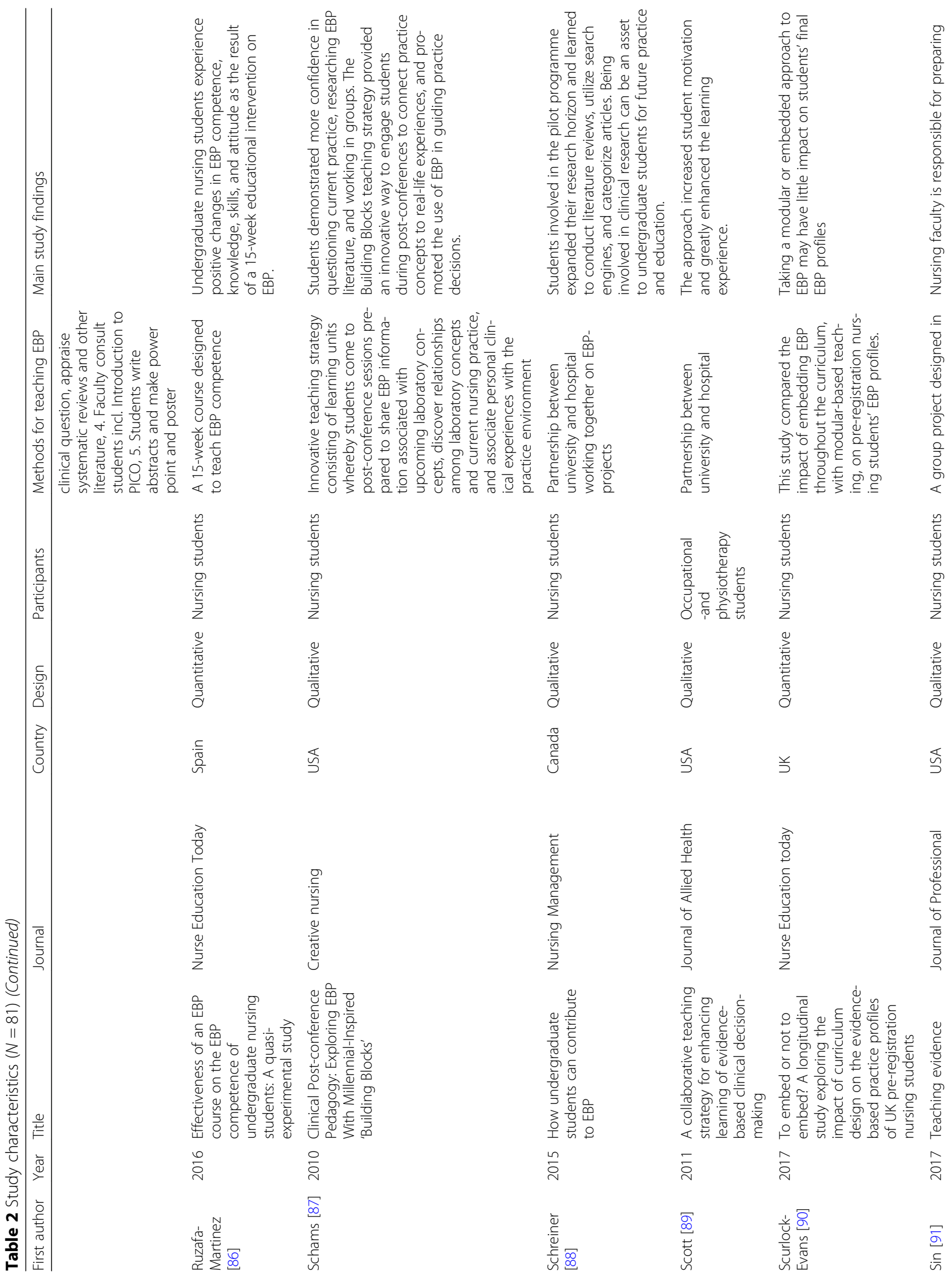




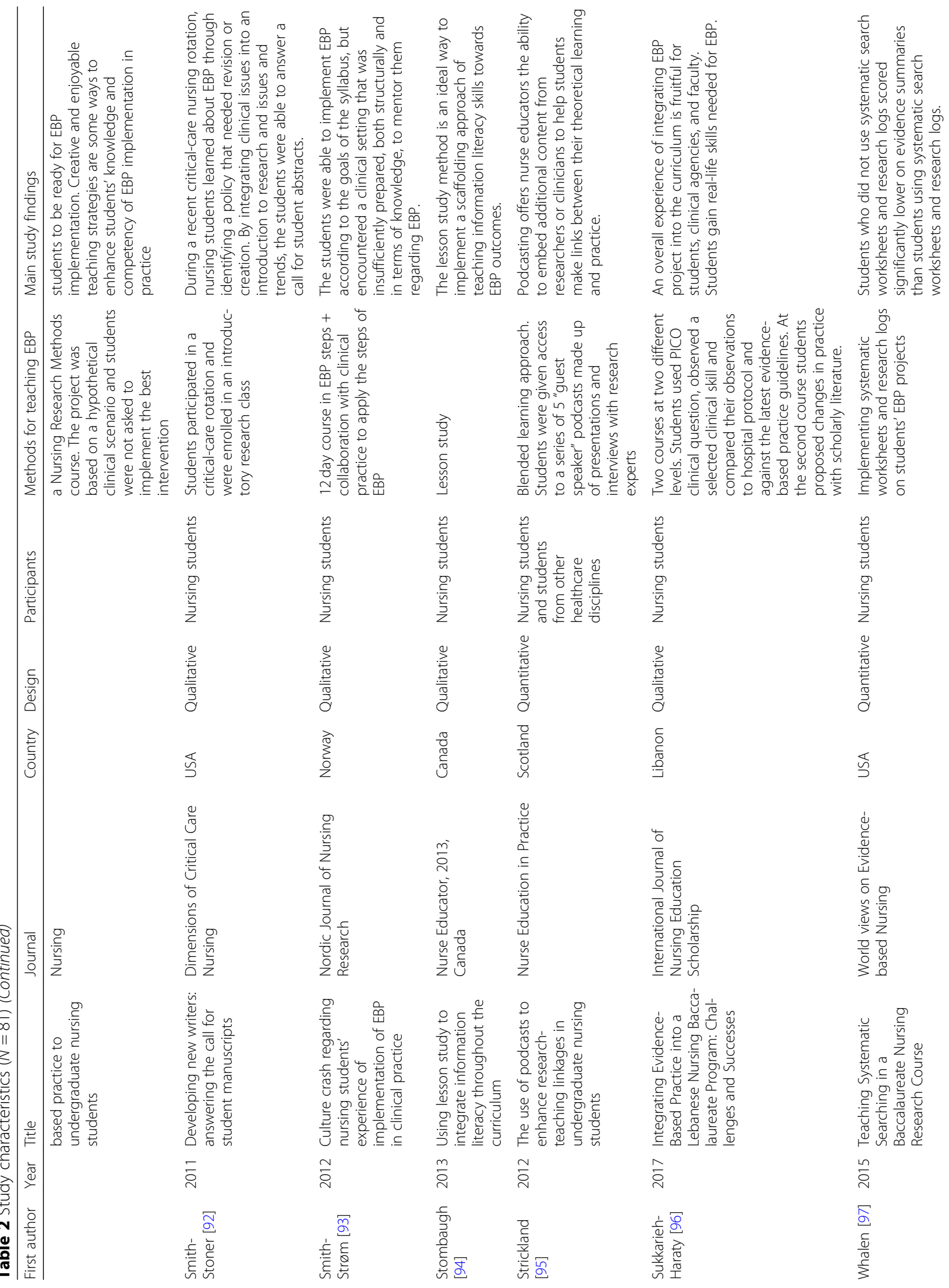




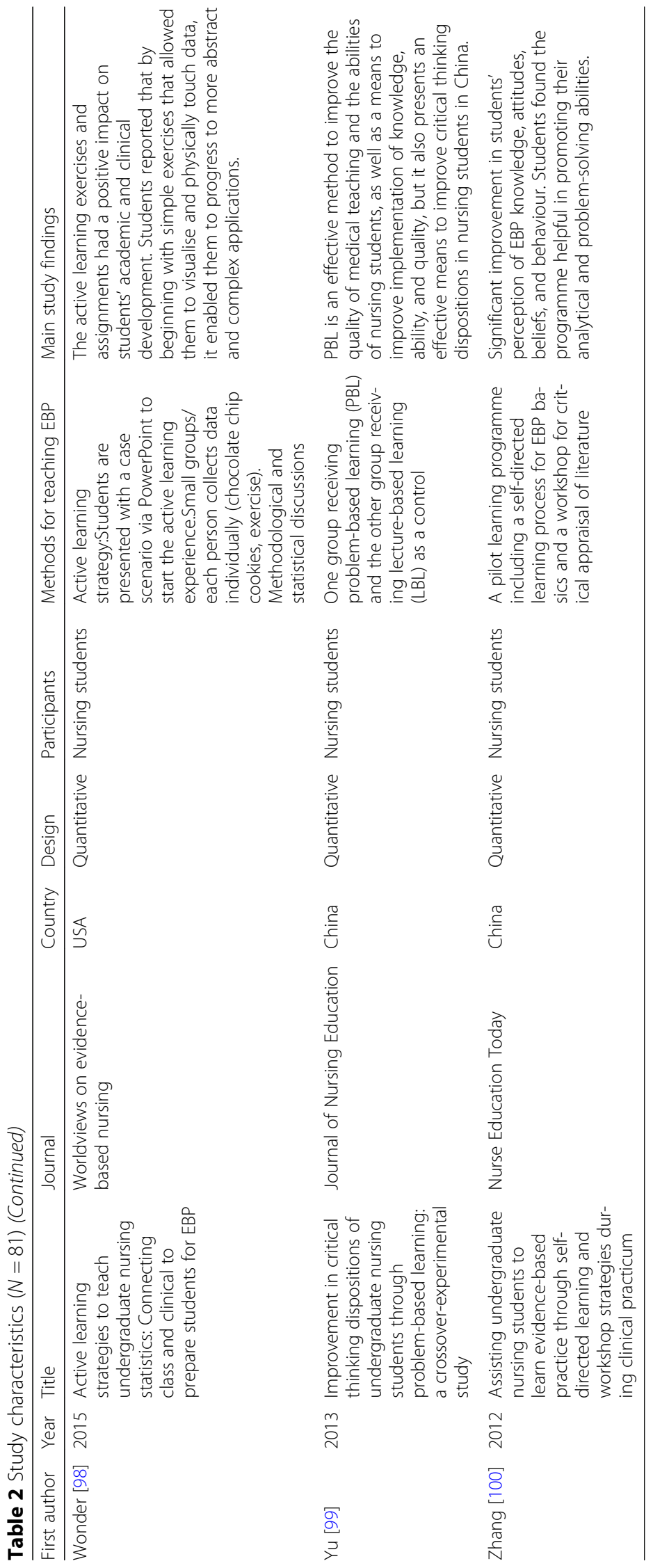




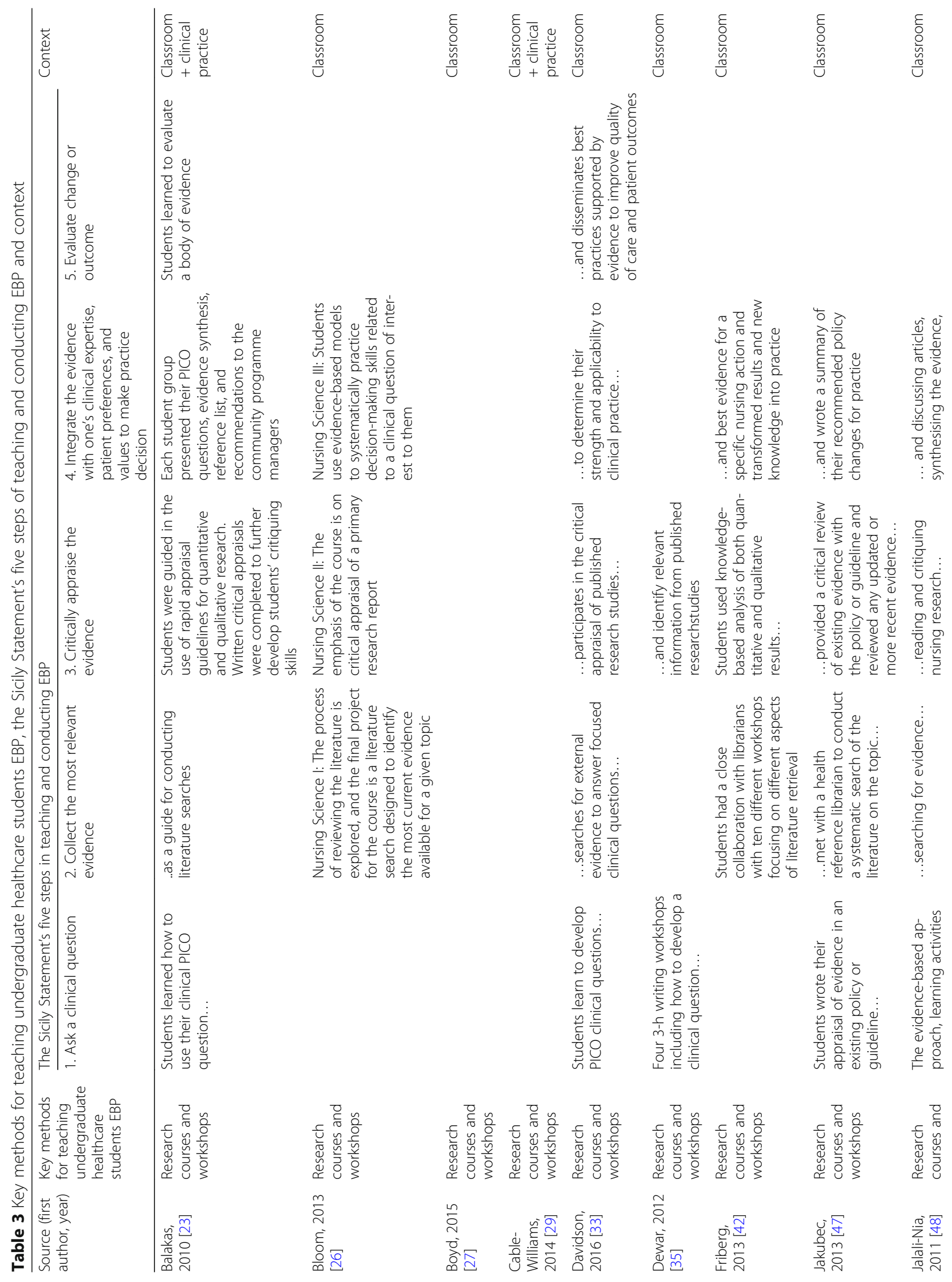




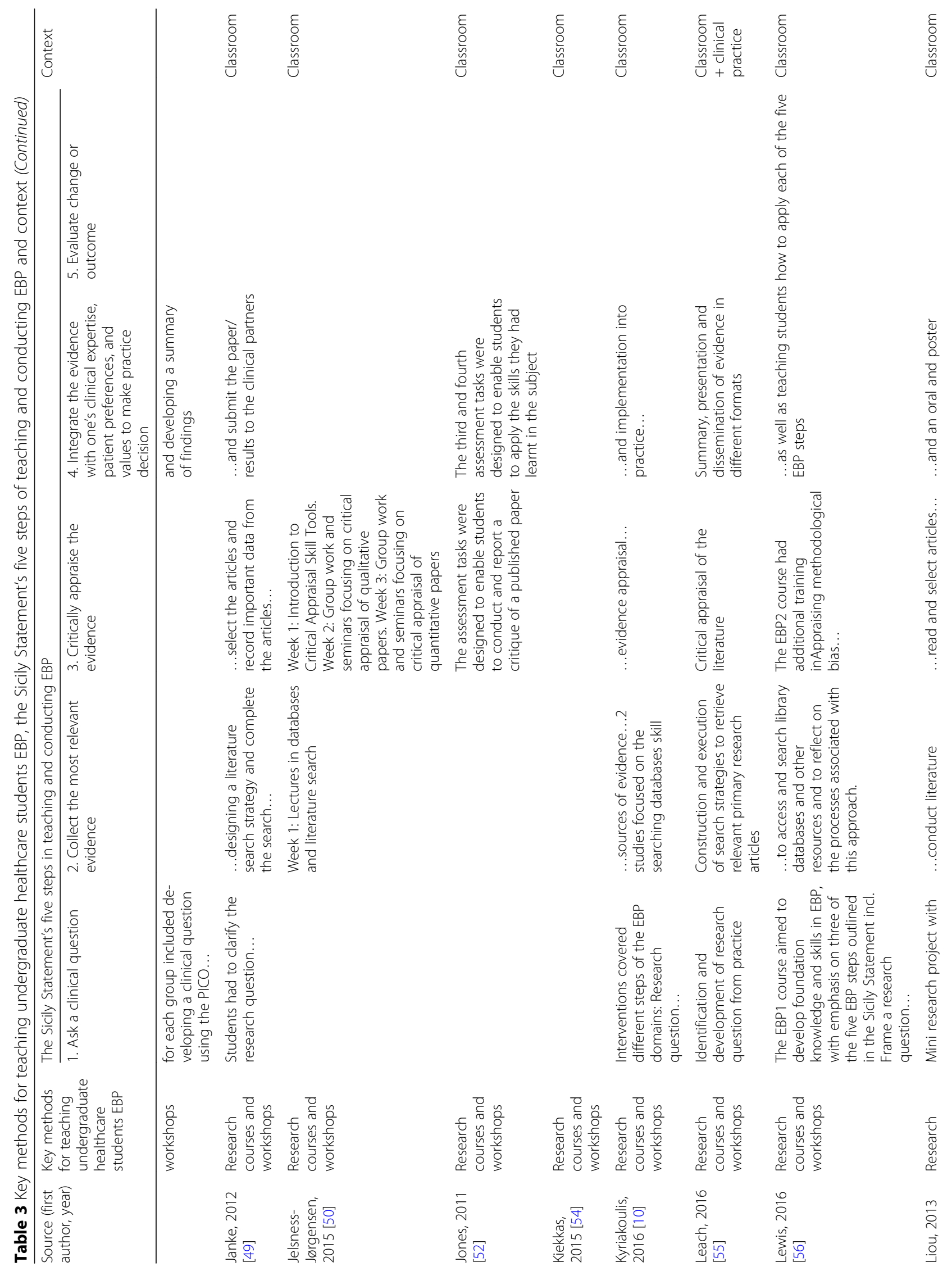




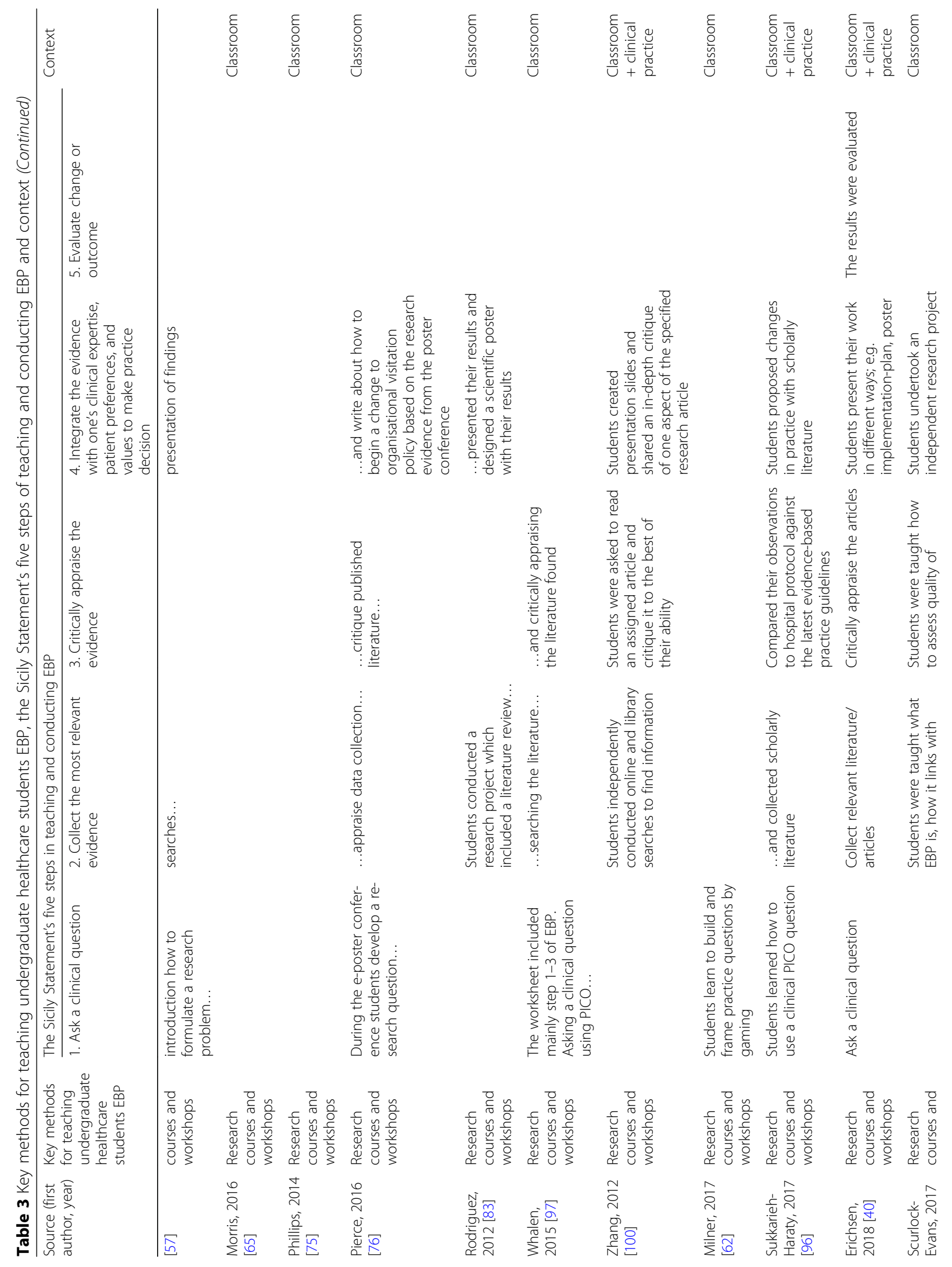




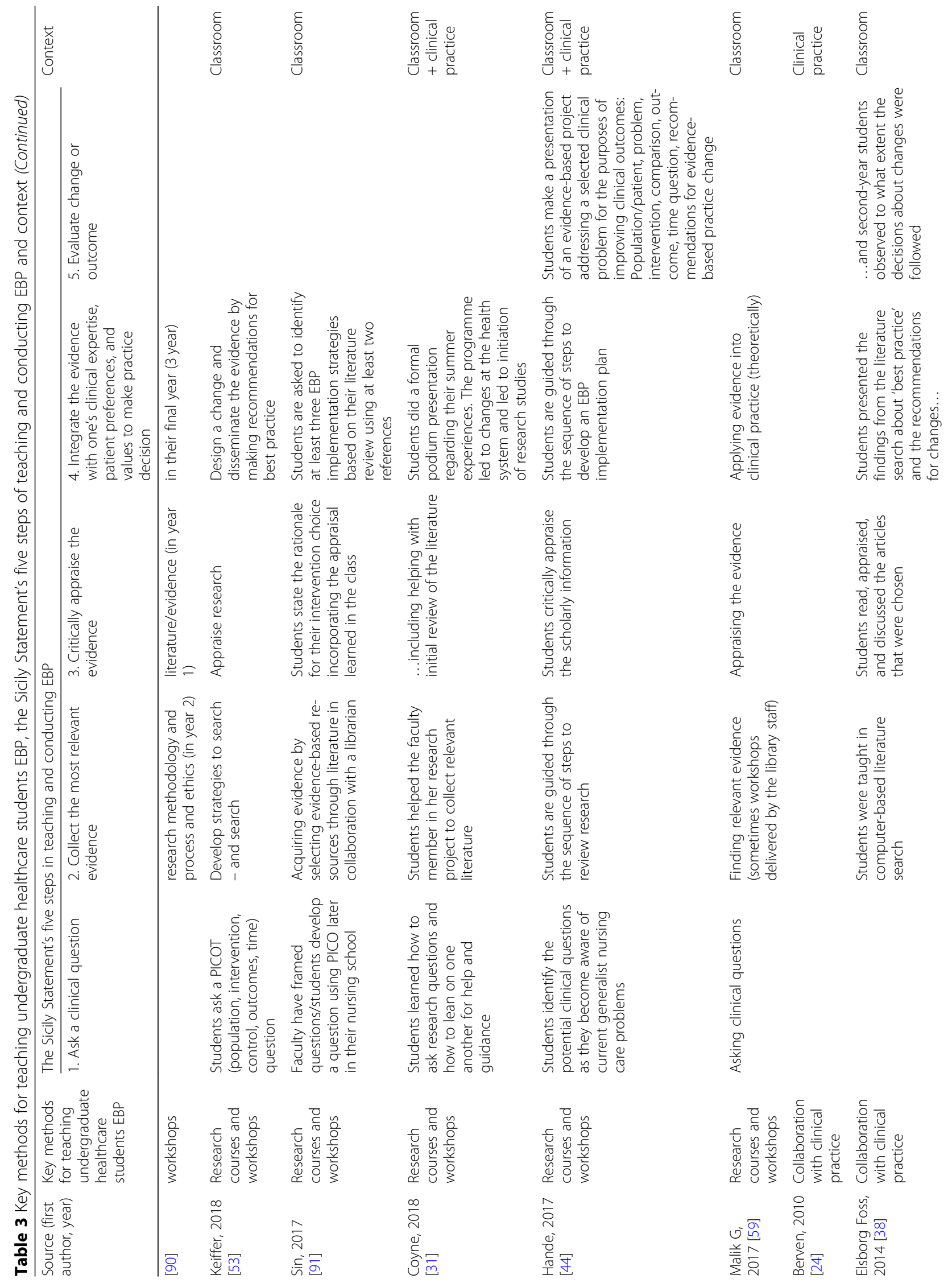




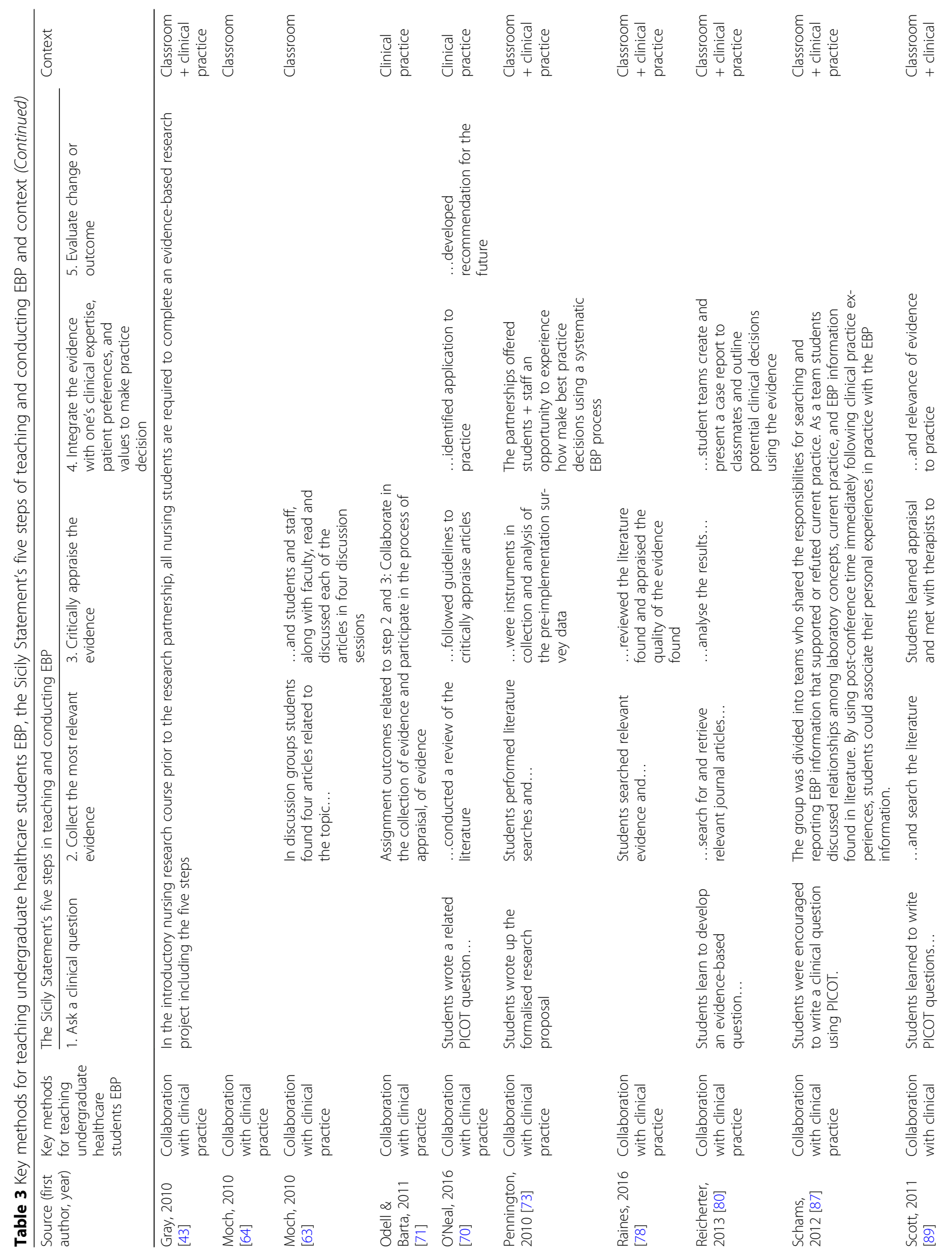




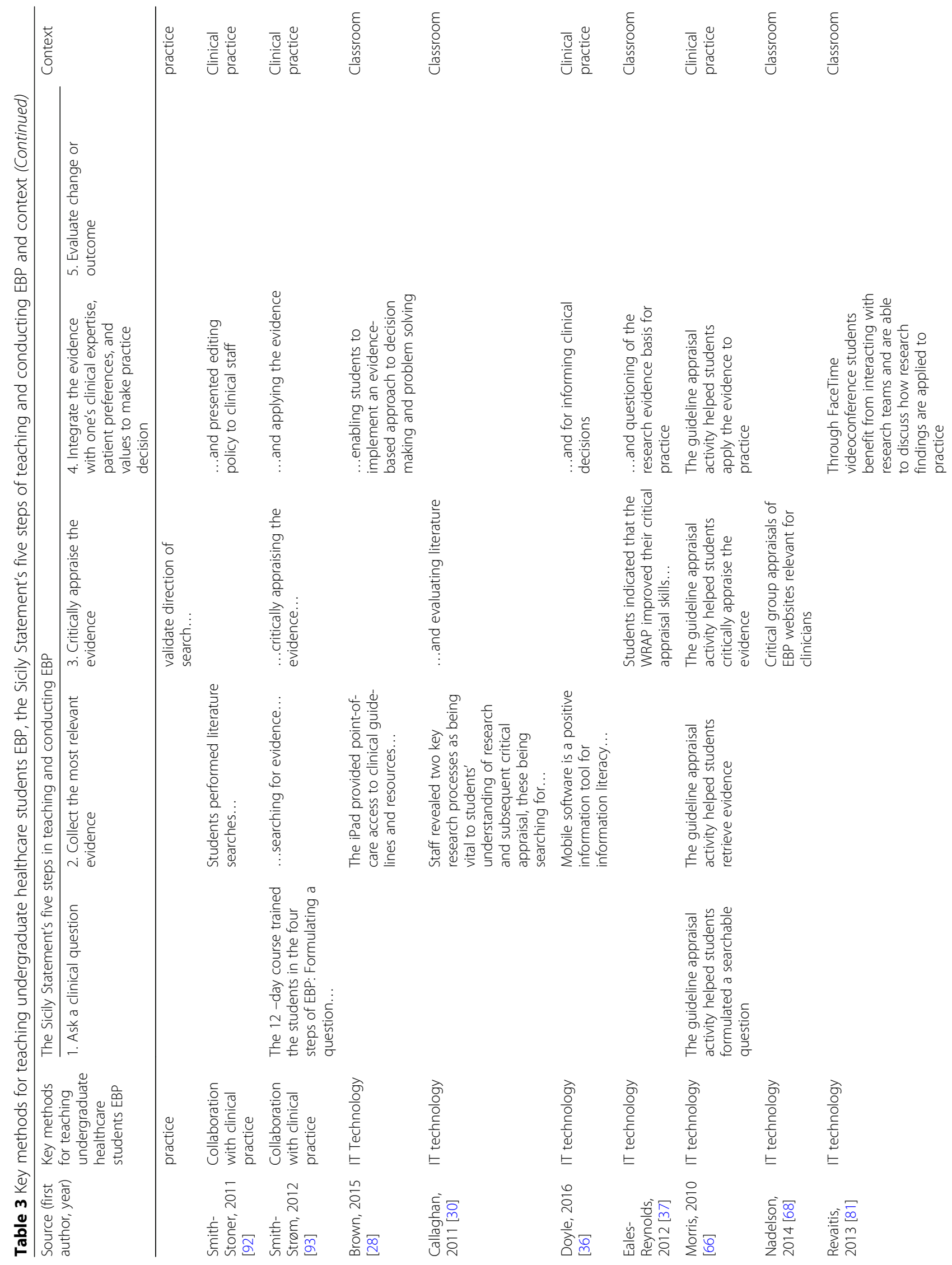



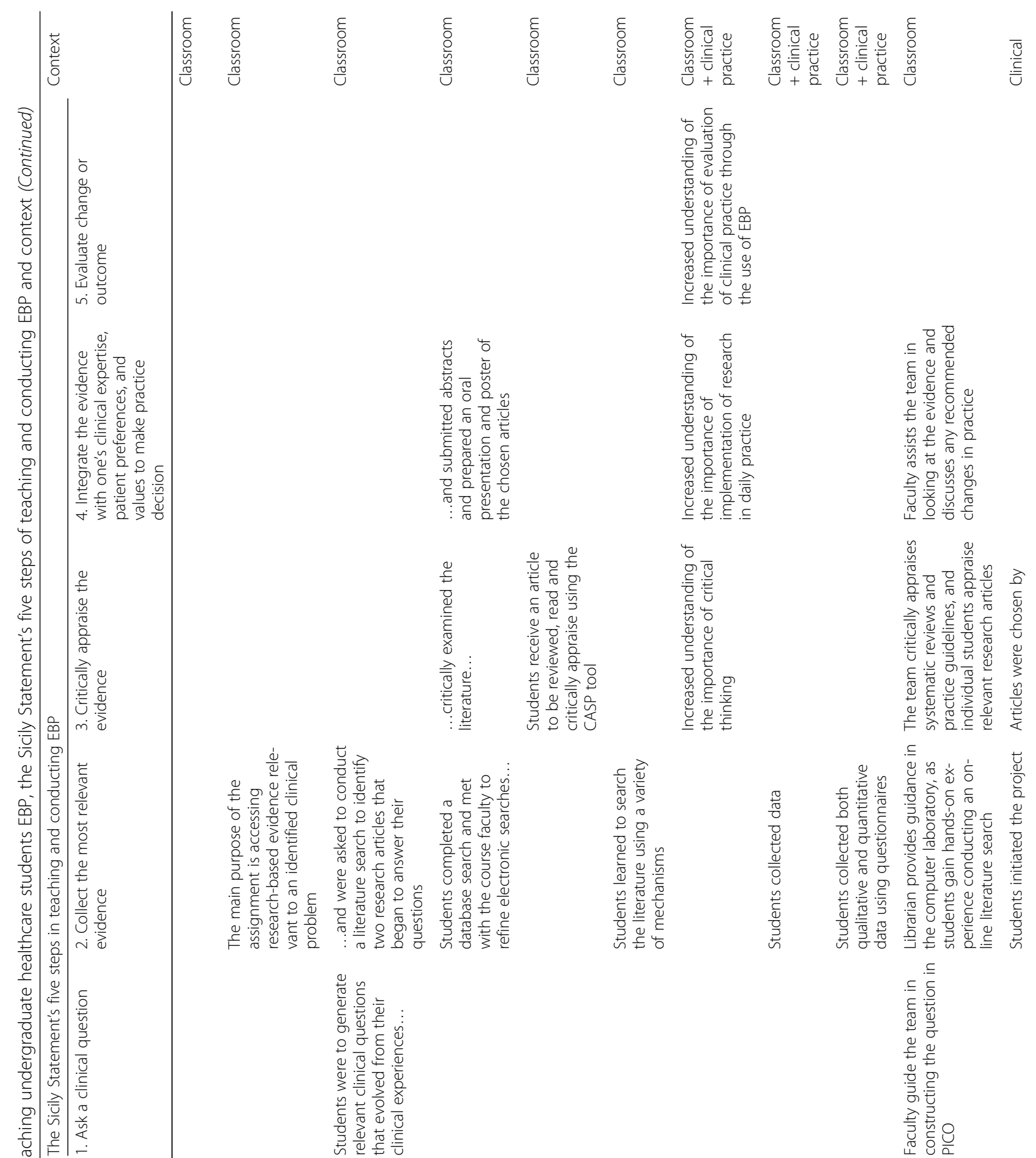

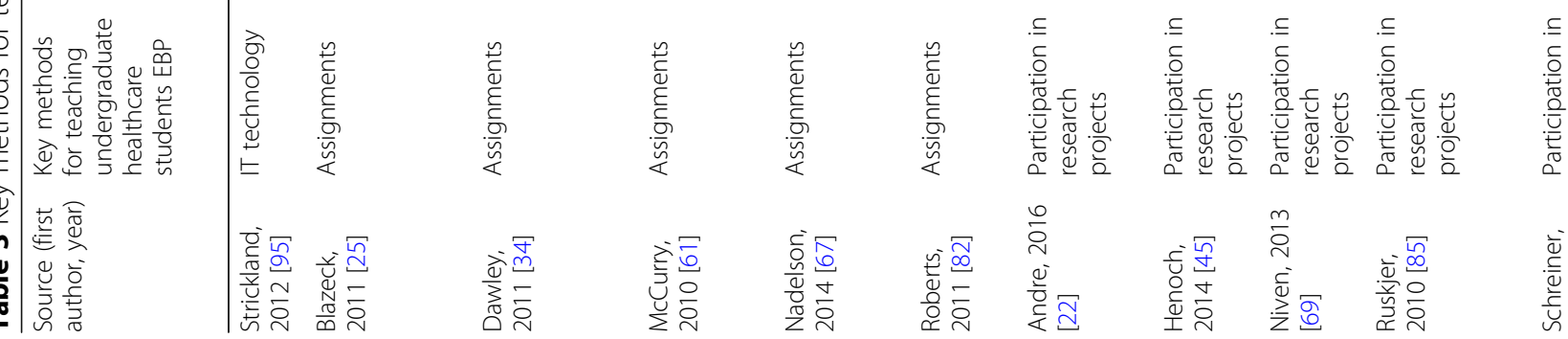




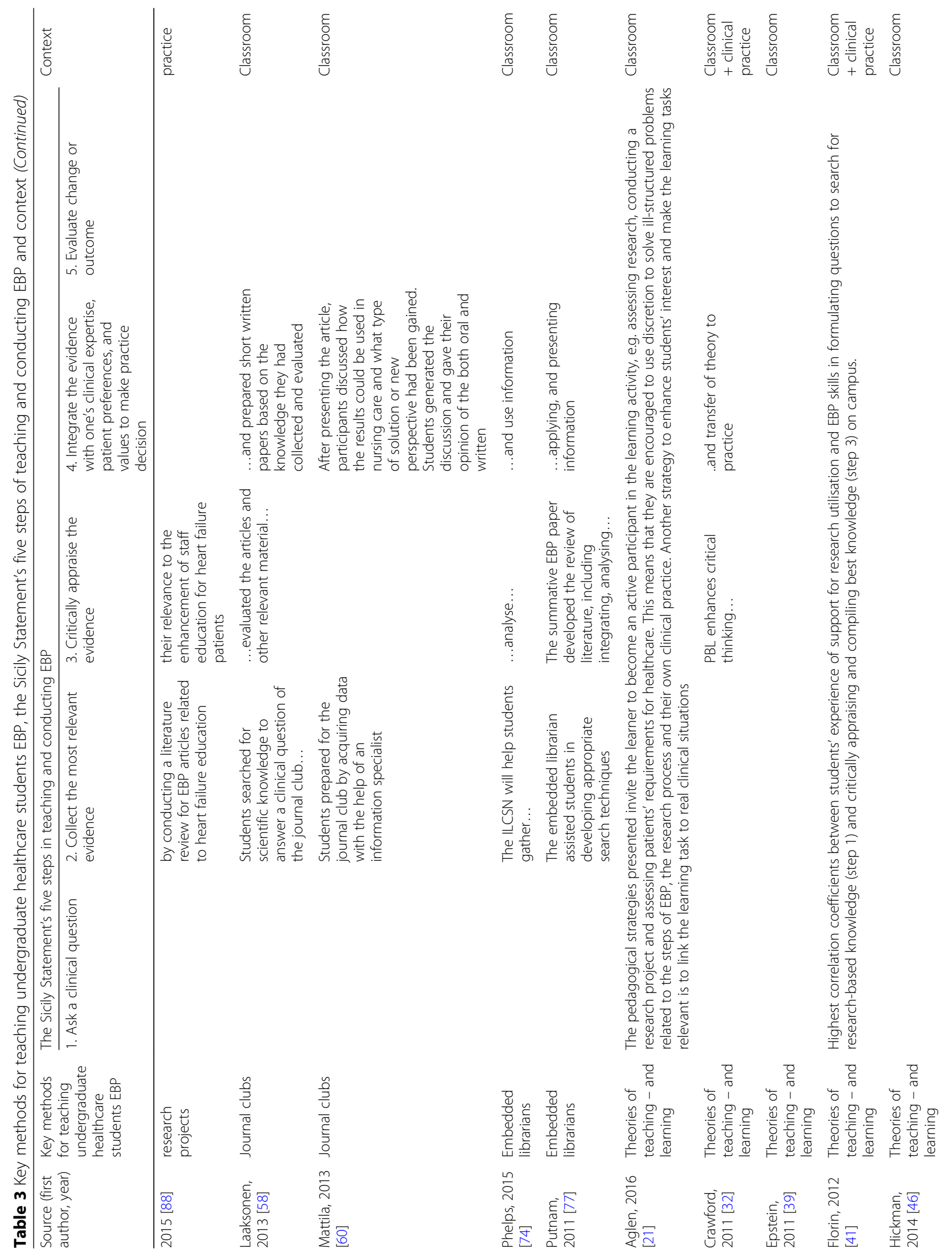




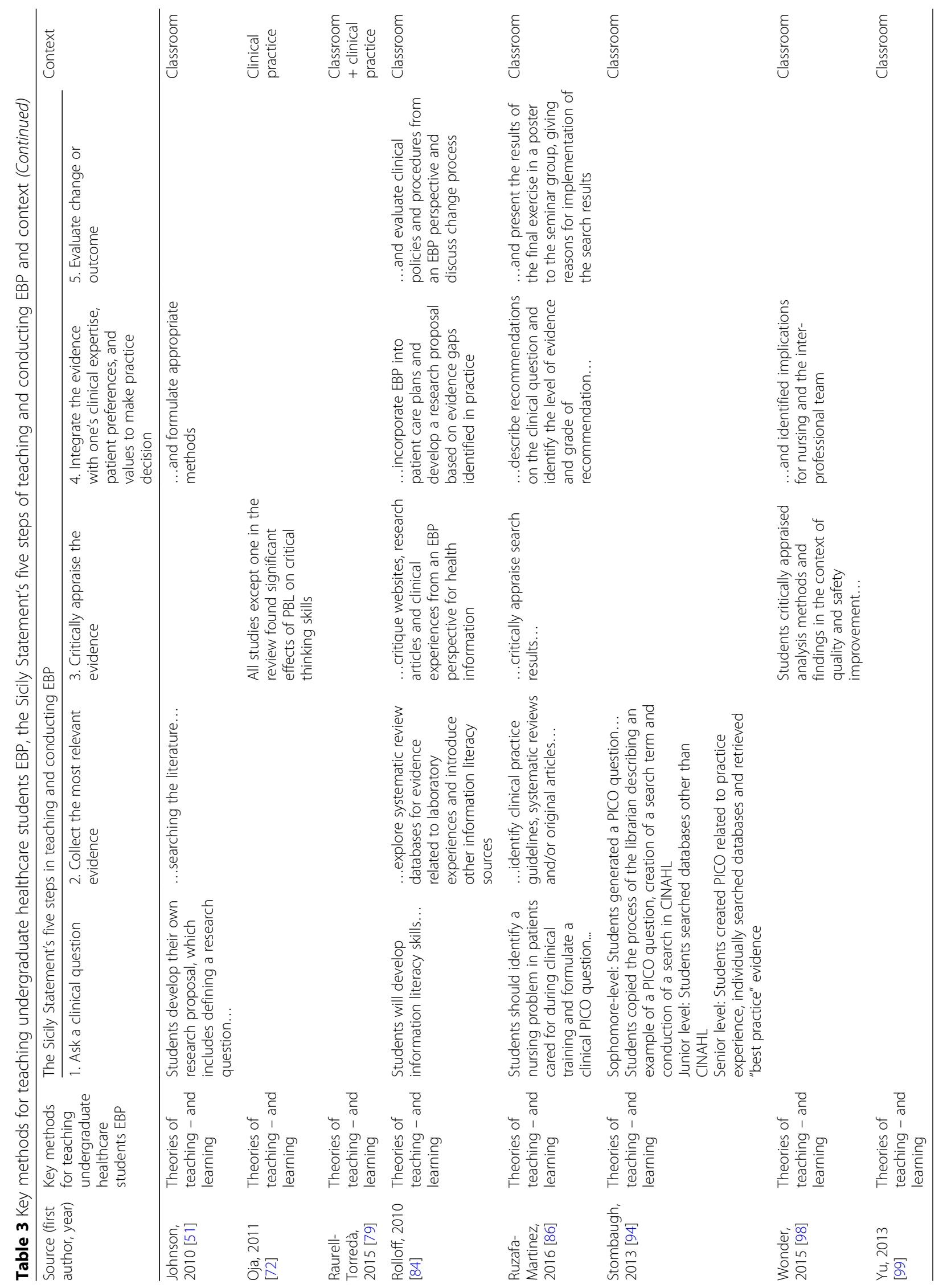


and ten studies described one step. Twelve studies had no description of any of the steps.

The steps most often referred to were step two, three, and four. Step two, "Collect the most relevant evidence", was mentioned in 58 studies. Step three, "Critically appraise the evidence", was referred to in 55 studies, while step four, "Integrate the evidence with one's clinical expertise, patient preferences, and values to make practice decision", was mentioned in 51 studies. Step one, "Ask a clinical question", and step five, "Evaluate change or outcome" was referred to in 36 and 14 studies, respectively. Seven out of the eleven studies referring to all of the Sicily Statement's five steps were identified under the key methods "Research courses and workshops" and "Collaboration with clinical practice".

The context in which the studies were conducted was primarily classroom settings $(n=52)$. Twenty studies described context as a combination of classroom and clinical practice, and nine studies were conducted in clinical practice.

Out of the 68 studies which included the seven key methods, 24 out of 32 "Research courses and workshops" were conducted in classrooms, while "Collaboration with clinical practice" was conducted in a combination of classroom and clinical practice $(n=6)$, clinical practice $(n=5)$, or classrooms $(n=3)$. "IT technology" was used in classrooms $(n=6)$ or clinical practice $(n=2)$. "Assignments" were conducted in classroom settings only $(n=5)$, while "Participation in research projects" took place in a combination of classroom and clinical practice $(n=3)$, classroom $(n=1)$ or clinical practice $(n=1)$. "Embedded librarians" $(n=2)$ and "Journal clubs" $(n=2)$ both took place in classroom settings.

\section{Discussion}

This study provides an overview of existing EBP teaching methods including The Sicily Statement's steps of teaching and conducting EBP with respect to undergraduate healthcare students both in classrooms and in clinical practice.

It is beyond the scope of this review to interpret all the findings of the included studies. The findings discussed below are the key methods most frequently identified in the thematic analysis: "Research courses and workshops" and "Collaboration with clinical practice", as well as the key methods most positively referred to in main findings of the studies: "IT technology", "Embedded librarians", and "Journal clubs". Despite the scarce use of the last three methods ("IT technology", "Embedded librarians", "Journal clubs") these can however provide ideas for how to teach EBP in the future. Furthermore, the scoping review provides useful information as to which of the Sicily Statement's five steps of teaching and conducting EBP are taught in the various methods and whether one particular method is more useful and applicable than others in a particular learning setting, depending on the context and the learning outcomes. Lecturers, senior lecturers and others who teach EBP at undergraduate healthcare educational institutions can benefit from this information and gain inspiration and ideas for teaching EBP. We are aware that other studies have addressed issues such as teachers' competencies required for teaching EBP, which we do consider important in order to standardise and improve education in EPB. Interestingly, a study has identified specific sets of EBP core competencies for teachers, which are classified within the 5-step model of EBP [101]. However, since our primary focus was on methods for teaching EBP to undergraduate healthcare students the aspect of teacher's competencies has not been further investigated.

Overall, the first 4 steps of the Sicily Statement could more easily be identified. However the last and fifth step proved to be more difficult to identify which often is the case. Furthermore, our results tend to point to the fact that the fifth step is often more theoretically linked at the undergraduate level and that a more specified implemtation and evaluation of the EBP process takes place at a more advanced level.

\section{Research courses and workshops}

Research courses and workshops were the most frequently used methods for teaching EBP. The frequent use of this method is in agreement with the systematic review by Kyriakoulis et al., where eight of the 20 methods for teaching EBP were research courses, workshops or similar sessions [10] and Young et al., where three out of five methods used for teaching evidencebased healthcare (EBHC) were workshops [2]. The majority of the studies concerning "Research courses and workshops", referred to three or more of the Sicily Statement's five steps of teaching and conducting EBP [10, $23,26,31,33,40,42,44,47-49,53,55-57,59,76,90$, 91, 96, 97, 100]. Despite the fact that the fifth step was included in some studies, it was not clear what was covered by the evaluation process, and additionally, if it was part of the students' assignment work alone or if there was a link to clinical practice. The majority of the research courses and workshops were conducted in classrooms. According to Young et al., EBHC courses can improve appraisal skills in nurses, occupational therapists and physiotherapists, among others [2]. However, further assessments and analyses of the courses and workshops found in this scoping review must be made to ensure that the content and outcomes are applicable in similar contexts.

\section{Collaboration with clinical practice}

In this scoping review, the key method for teaching EBP, "Collaboration with clinical practice" was identified 14 
times in the thematic analysis. In comparison, "collaboration with clinical practice" is only mentioned once as a method for teaching EBP in the review by Young et al. [2] and not mentioned in the systematic review by Kyriakoulis et al. [10]. The results of this scoping review suggest that collaboration with clinical practice is a frequently used method for teaching EBP with respect to undergraduate healthcare students. The rare use of this method in the review by Kyriakoulis et al. and the review by Young et al. might be explained by the type of participants included in these reviews. Only two studies included undergraduate students in the disciplines of nursing, physiotherapy or occupational therapy: in the review by Young et al. and the review by Kyriakoulis [2, 10]. Along this line, a review on teaching EBM to medical students found weak and inconsistent results from a limited number of studies on the effect of clinically integrated methods on knowledge, attitudes, and skills [102]. Collaboration with clinical practice might be more fundamental among undergraduate students in the disciplines of nursing, physiotherapy or occupational therapy, compared to undergraduate students in medicine primarily included in the other reviews $[2,10]$.

Half of the studies identified in relation to "Collaboration with clinical practice", referred to four or five of the Sicily Statement's steps [38, 43, 70, 73, 80, 87, 89, 93]. In two of the studies, the steps were taught directly in clinical practice as part of the students' clinical education [70,93], and unlike the research courses and workshops methods, the last step of evaluation of change or outcome is carried out either partly or entirely in a clinical context. The main findings of all eight studies indicate that collaboration with clinical practice is an effective way of teaching EBP, both with the combination of classrooms and clinical practice settings and in clinical practice settings alone. Despite being a recommended strategy in the literature, a recent literature review points to the fact that EBP teaching strategies including clinical activities in nursing students seems less prioritised [12].

\section{IT technology}

The key method, "IT technology", described tools, such as mobile devices, video resources and websites, among others, used in classrooms or clinical practice for seeking information in relation to EBP. In clinical practice, mobile devices were used to seek information regarding EBP search strategies, critical appraisal of clinical guidelines [66], and specific task-oriented information in relation to clinical practice [36]. Despite the reported improvement in knowledge and skills in relation to EBP and appraisal of clinical guidelines, the use of mobile devices was reported as low [66]. In classrooms, the use of IT technology as a method for teaching EBP was reported as mainly positive. Today, most students have access to IT equipment and this technology could be integrated in classrooms and clinical practice to seek information regarding EBP. In the review by Kyriakoulis et al. the results support our findings; that IT technology can be an effective method for teaching EBP with respect to undergraduate healthcare students [10].

\section{Journal clubs}

"Journal Clubs" as a method for teaching EBP was only described in two studies in this scoping review. However, the findings indicated that the method improved students' skills in reading articles and understanding evidence-based nursing [60], and promoted competenceis needed to deliver evidence-based care [58]. The studies included two and three steps, respectively, proposed by the Sicily Statement [3]. Additional steps may advantageously be incorporated into future journal clubs to ensure the quality of healthcare. Young et al. referred to four reviews describing a positive effect of journal clubs as a method for teaching EBP [2]. However, none of the reviews included Professional Bachelor Degree healthcare students. Further studies must be conducted to assess the effectiveness of journal clubs as a method for teaching EBP in Professional Bachelor Degree healthcare courses and to study the opportunity of incorporating all of the Sicily Statement's five steps for teaching and conducting EBP.

\section{Embedded librarians}

In two studies librarians were introduced to teach students information literacy [74, 77]. Librarians are experts in this field and are able to teach students the skills essential to EBP [74]. Librarians can support students in establishing and managing effective search techniques and help with reviewing and critiquing the information found. Thus, students develop information literacy skills as required in practice [77]. Research librarians who are embedded as part of a research course for teaching undergraduate healthcare students EBP may be an effective way of ensuring a complete introduction to the Sicily Statement's five steps of teaching and conducting EBP. The first three steps can be taught in classrooms, followed by practical exercises in the last two steps in clinical practice.

\section{Implications for practice}

The majority of the key methods found for teaching EBP were "Research courses and workshops" and "Collaboration with clinical practice", whereas "Journal Clubs" and "Embedded librarians" were identified only twice. The frequent use of research courses and workshops as methods for teaching EBP may stem from a tradition of classroom lectures and is a relatively manageable way to 
teach EBP. The findings from this scoping study however suggest that other methods for teaching EBP with respect to undergraduate students exist. Journal clubs could be incorporated as a supplement to classroom lectures or as part of collaboration with clinical practice. Librarians may advantageously be introduced in research courses and workshops. The librarians can help students gain control of EBP definitions and concepts, and master search techniques before entering clinical practice. The effect of journal clubs and embedded librarians on students' EBP competencies should however be investigated further before being incorporated into Professional Bachelor's Degree curricula.

EBP education based on the Sicily Statement's five steps, demanded both internationally and nationally, implies an introduction to all of the Sicily Statement's five steps of teaching and conducting EBP at undergraduate level $[5,6$, 9]. At present, the majority of the methods found for teaching EBP only include 2-4 steps. In line with these results, a recent review found that the majority of evaluated EBP educational interventions are focused on a single step (step 3, critically appraising evidence) of the five steps of teaching and conducting EBP [103]. This research adds to the statement that an effort must be made to incorporate all five steps of the Sicily Statement in an educational and cooperative way in order to ensure that undergraduate healthcare students are qualified to work in an evidencebased manner.

We did not review available assessment methods for evaluation of EBP education interventions or programmes in this study. The additional importance of this field and the apparent lack of valid evaluation methods have been extensively highlighted in other studies and needs to be taken into account when applying methods for teaching EPB [104, 105].

\section{Strengths and limitations}

The scoping review presents an updated overview of existing methods for teaching EBP with respect to undergraduate healthcare students, including study specific recommendations for teaching methods to be used in future curricula. It follows recommended guidelines for a priori design requirements and transparent reporting $[13,16]$.

Limitations are however found in relation to the search strategy. Our search did not include literature published before 2010 and due to time constraints, a limited number of databases were searched, which entails the risk that not all relevant literature was identified. Furthermore, the search terms used identified primarily undergraduate nursing students, despite a thorough search for all undergraduate students in the disciplines of nursing, physiotherapy, occupational therapy, radiography, and biomedical laboratory science.
Other search terms might have captured these health disciplines to a greater extent. An alternative explanation for the large occurrence of studies regarding nursing students could be that there is a greater publishing tradition in this field. However, the methods for teaching EBP can to a certain extent, be introduced to undergraduate students in the other health disciplines.

\section{Conclusion}

Consistent with our objective, this scoping review has provided an extensive overview of literature describing methods for teaching EBP regarding undergraduate healthcare students. The two key methods most often identified were "Research courses and workshops" and "Collaboration with clinical practice". Despite the first method often being used in this scoping review, as well as in other reviews, fewer of the Sicily Statement's five steps of teaching and conducting EBP were referred to, and if the fifth step of evaluation of change or outcome was included, the description of content was often unclear.

On the contrary, "Collaboration with clinical practice", the second most used teaching method, more often referred to four or five steps, making this method an effective approach for teaching EBP while ensuring incorporation of several of the steps. Unlike the Research courses and workshop methods, the last step of evaluation is carried out partly or entirely in a clinical context.

Overall, our results tend to show that the evaluation step is often theoretically linked at the undergraduate level. Despite the small number of studies describing 'Journal clubs' and 'Embedded librarians', these teaching methods could advantageously be incorporated in the classroom context and could ensure a complete introduction to all five steps.

On the basis of our findings, we argue that future research should focus on identifying methods for teaching EBP that incorporate as many of the Sicily Statement's five steps of teaching and conducting EBP as possible. Journal clubs and embedded librarians could be further looked into as methods to support the more established methods for teaching EBP across all undergraduate healthcare disciplines.

\section{Acknowledgements}

The authors would like to thank research assistants Morten Puck, Martin Mau and Susanne Pommergård for their valuable work in reviewing and editing tables.

\section{Authors' contributions}

AST, HKK, CML contributed in designing the study. AST and AFC conducted the literature search. AST, HKK and CML screened the titles and abstracts. AST, HKK, CML extracted data from the studies. AST and HKK performed a synthesis of study results. AST, HKK, CML and AFC interpreted the data. CML and AST drafted the manuscript. All the listed authors have contributed to and approved the final manuscript.

\section{Funding}

This project is funded by internal funds granted by Health Sciences Research Centre, UCL University College, Odense, Denmark. The funding part had no 
role in the design of the study, the collection, analysis and interpretation of the data, or in writing the manuscript.

\section{Availability of data and materials}

The data used and analysed during the current scoping review are available from the corresponding author on reasonable request.

\section{Ethics approval and consent to participate}

Not applicable.

\section{Consent for publication}

Not applicable.

\section{Competing interests}

The authors declare that they have no competing interests.

\section{Author details}

${ }^{1}$ Health Sciences Research Centre, UCL University College, Niels Bohrs Allé 1, 5230 Odense M, Denmark. ²Department of Physiotherapy, UCL University College, Niels Bohrs Allé 1, 5230 Odense M, Denmark. ${ }^{3}$ Research Service, UCL Library, UCL University College, Niels Bohrs Allé 1, 5230 Odense M, Denmark. ${ }^{4}$ Research Unit for Musculoskeletal Function and Physiotherapy, Department of Sports Science and Clinical Biomechanics, University of Southern Denmark, Campusvej 55, 5230 Odense M, Denmark. ${ }^{5}$ Department of Clinical Research, University of Southern Denmark, Winsløwparken 19, 5000 Odense, Denmark.

Received: 17 December 2018 Accepted: 23 June 2019

Published online: 11 July 2019

\section{References}

1. Dizon JM, Grimmer-Somers K, Kumar S. Effectiveness of the tailored Evidence Based Practice training program for Filipino physical therapists: a randomized controlled trial. BMC Med Educ. 2014;14. https://doi.org/10. 1186/1472-6920-14-147.

2. Young T, Rohwer A, Volmink J, Clarke M. What are the effects of teaching evidence-based health care (EBHC)? Overview of systematic reviews. PLOS One. 2014;9(1):e86706

3. Dawes M, Summerskill W, Glasziou P, Cartabellotta A, Martin J, Hopayian K, et al. Sicily statement on evidence-based practice. BMC Med Educ. 2005;5(1):1.

4. Burns HK, Foley SM. Building a foundation for an evidence-based approach to practice: teaching basic concepts to undergraduate freshman students. J Prof Nurs. 2005;21(6):351-7.

5. Daly M, DeAngelis T. Teaching evidence-based practice across curricula-an overview of a professional development course for occupational therapy educators. Occup Ther Health Care. 2017;31:102-9.

6. Greenhalg T, Howick J, Maskrey N. Evidence-based medicine: a movement in crisis? BMJ. 2014;348:g3725.

7. Styrelsen for Videregående Uddannelser, Uddannelses- og Forskningsministeriet. Direction for the work of single profession development groups. 2015; Available at: http://www.ft.dk/samling/20151/ almdel/ufu/bilag/166/1637938/index.htm. Accessed 17 Aug 2017.

8. Ministry of Higher Education and Science. The Danish higher education system. 2016; Available at: https://ufm.dk/uddannelse/anerkendelse-ogdokumentation/dokumentation/europass/diploma-supplement/ standardbeskrivelse-af-higher-education-in-denmark/ds-standardbeskrivelsepdf. Accessed 7 June 2019.

9. Kristensen H, Nøhr-Jensen L, Stokholm G, Berg P, Borg-Hansen K, Pedersen K, et al. Evidence-based practice - Health educations University College Lillebaelt - Curiculum revision. 2016;1:2-10.

10. Kyriakoulis K, Patelarou A, Laliotis A, Wan AC, Matalliotakis M, Tsiou C, et al. Educational strategies for teaching evidence-based practice to undergraduate health students: systematic review. J Educ Eval Health Prof. 2016;13:34.

11. Ghaffari R, Shapoori S, Binazir MB, Heidari F, Behshid M. Effectiveness of teaching evidence-based nursing to undergraduate nursing students in Iran: a systematic review. Res Dev Med Educ. 2018;7(1):8-13.

12. Horntvedt MT, Nordsteien A, Fermann T, Severinsson E. Strategies for teaching evidence-based practice in nursing education: a thematic literature review. BMC Med Educ. 2018;18(1):172.

13. Munn Z, Peters MD, Stern C, Tufanaru C, McArthur A, Aromataris E. Systematic review or scoping review? Guidance for authors when choosing between a systematic or scoping review approach. BMC Med Res Methodol. 2018;18(1):143.

14. Merriam-Webster. Classroom. 2017; Available at: https://www.merriamwebster.com/dictionary/classroom. Accessed 30 Mar 2017.

15. Segen's Medical Dictionary. Clinical practice. 2011; Available at: http://medicaldictionary.thefreedictionary.com/clinical+practice. Accessed 30 Mar 2017.

16. The Joanna Briggs Institute. The Joanna Briggs Institute reviewer's manual: 2015 edition / supplement. 2015; Available at: https://nursing.Isuhsc.edu/JBI/ docs/ReviewersManuals/Scoping-.pdf. Accessed 7 June 2019.

17. Joanna Briggs Institute. JBI reviewer's manual. 2019; Available at: https://wiki. joannabriggs.org/display/MANUAL. Accessed 7 June 2019.

18. Communiqué of the Conference of European Ministers Responsible for Higher Education. The Bologna Process 2020 - The European higher education area in the new decade. 2009; Available at: http://www.ehea.info/ media.ehea.info/file/2009 Leuven_Louvain-la-Neuve/06/1/Leuven_Louvainla-Neuve_Communique_April_2009_595061.pdf. Accessed 15 May 2019.

19. Paniagua H. Planning research: methods and ethics. Pract Nurs. 2002;13(1):22-5.

20. Cronin P, Ryan F, Coughlan M. Undertaking a literature review: a step-bystep approach. Br J Nurs. 2008;17(1):38-43.

21. Aglen B. Pedagogical strategies to teach bachelor students evidence-based practice: a systematic review. Nurse Educ Today. 2016;36:255-63.

22. Andre B, Aune AG, Braend JA. Embedding evidence-based practice among nursing undergraduates: results from a pilot study. Nurse Educ Pract. 2016;18:30-5.

23. Balakas K, Sparks L. Teaching research and evidence-based practice using a service-learning approach. J Nurs Educ. 2010;49(12):691-5.

24. Berven L. Students collaborate with nurses from a nursing home to get an evidence based practice...Fourth European Nursing Congress. J Clin Nurs. 2010;19:78.

25. Blazeck A, Klem ML, Miller TH. Building evidence-based practice into the foundations of practice. Nurse Educ. 2011:36(3):124-7.

26. Bloom KC, Olinzock BJ, Radjenovic D, Trice LB. Leveling EBP content for undergraduate nursing students. J Prof Nurs. 2013;29(4):217-24.

27. Boyd MR, Baliko B, Polyakova-Norwood V. Using debates to teach evidencebased practice in large online courses. J Nurs Educ. 2015;54(10):578-82.

28. Brown J, McCrorie P. The iPad: tablet technology to support nursing and midwifery student learning: an evaluation in practice. Comput Inform Nurs. 2015;33(3):93-8.

29. Cable-Williams B, Rush J, Mowry A, Macleod A, Gilmer C, Graham C, et al. An educational innovation to foster evidence-informed practice. J Nurs Educ. 2014;53(3):S55-8.

30. Callaghan L, Lea SJ, Mutton L, Whittlesea E. Enhancing health students' understanding of generic research concepts using a web-based video resource. Nurse Educ Pract. 2011:11(6):375-9.

31. Coyne BM, Kennedy C, Self A, Bullock L. A comprehensive approach to undergraduate nursing students' research experiences. J Nurs Educ. 2018;57(1):58-62.

32. Crawford TR. Using problem-based learning in web-based components of nurse education. Nurse Educ Pract. 2011;11(2):124-30.

33. Davidson SJ, Candy L. Teaching EBP using game-based learning: improving the student experience. Worldviews Evid Based Nurs. 2016; 13(4):285-93.

34. Dawley K, Bloch JR, Suplee PD, McKeever A, Scherzer G. Using a pedagogical approach to integrate evidence-based teaching in an undergraduate women's health course. Worldviews Evid Based Nurs. 2011;8(2):116-23.

35. Dewar SR. The evidence-based practice course as an opportunity for writing. Nurse Educ. 2012;37(4):143-4

36. Doyle GJ, Furlong KE, Secco L. Information literacy in a digital era: understanding the impact of mobile information for undergraduate nursing students. Stud Health Technol Inform. 2016:225:297-301.

37. Eales-Reynolds LJ, Gillham D, Grech C, Clarke C, Cornell J. A study of the development of critical thinking skills using an innovative web 2.0 tool. Nurse Educ Today. 2012;32(7):752-6.

38. Elsborg Foss J, Kvigne K, Wilde Larsson B, Athlin E. A model (CMBP) for collaboration between university college and nursing practice to promote research utilization in students' clinical placements: a pilot study. Nurse Educ Pract. 2014;14(4):396-402.

39. Epstein I, Santa Mina EE, Gaudet J, Singh MD, Gula T. Teaching statistics to undergraduate nursing students: an integrative review to inform our 
pedagogy. Int J Nurs Educ Scholarsh. 2011;8(1). https://doi.org/10.2202/ 1548-923X.2234.

40. Erichsen $\mathrm{T}$, Røkholt $\mathrm{G}$, Utne I. Kunnskapsbasert praksis i sykepleierutdanningen. Sykepleien Forskning. 2018;11(1):66-76.

41. Florin J, Ehrenberg A, Wallin L, Gustavsson P. Educational support for research utilization and capability beliefs regarding evidence-based practice skills: a national survey of senior nursing students. J Adv Nurs. 2012;68(4):888-97.

42. Friberg F, Lyckhage ED. Changing essay writing in undergraduate nursing education through action research: a Swedish example. Nurs Educ Perspect. 2013;34(4):226-32.

43. Gray MT. Research odyssey: the evolution of a research partnership between baccalaureate nursing students and practicing nurses. Nurse Educ Today. 2010;30(4):376-82.

44. Hande K, Ty Williams C, Robbins HM, Kennedy BB, Christenbery T. Leveling evidence-based practice across the nursing curriculum. J Nurse Pract. 2017;13(1):e17-22.

45. Henoch I, Jakobsson Ung E, Ozanne A, Falk H, Falk K, Kenne Sarenmalm E, et al. Nursing students' experiences of involvement in clinical research: an exploratory study. Nurse Educ Pract. 2014;14(2):188-94.

46. Hickman LD, Kelly H, Phillips JL. EVITEACH: a study exploring ways to optimise the uptake of evidence-based practice to undergraduate nurses. Nurse Educ Pract. 2014;14(6):598-604.

47. Jakubec SL, Astle BJ. Students connecting critical appraisal to evidencebased practice: a teaching-learning activity for research literacy. J Nurs Educ. 2013;52(1):56-8.

48. Jalali-Nia SF, Salsali M, Dehghan-Nayeri N, Ebadi A. Effect of evidencebased education on Iranian nursing students' knowledge and attitude. Nurs Health Sci. 2011;13(2):221-7.

49. Janke R, Pesut B, Erbacker L. Promoting information literacy through collaborative service learning in an undergraduate research course. Nurse Educ Today. 2012;32(8):920-3.

50. Jelsness-Jørgensen L. Does a 3-week critical research appraisal course affect how students perceive their appraisal skills and the relevance of research for clinical practice? A repeated cross-sectional survey. Nurse Educ Today. 2015;35(1):e1-5.

51. Johnson N, List-Ivankovic J, Eboh WO, Ireland J, Adams D, Mowatt E, et al. Research and evidence based practice: using a blended approach to teaching and learning in undergraduate nurse education. Nurse Educ Pract. 2010;10(1):43-7.

52. Jones SC, Crookes PA, Johnson KM. Teaching critical appraisal skills for nursing research. Nurse Educ Pract. 2011;11(5):327-32.

53. Keiffer MR. Engaging Nursing Students: Integrating Evidence-Based Inquiry, Informatics, and Clinical Practice. Nurs Educ Perspect. 2018;39(4):247-249.

54. Kiekkas P, Panagiotarou A, Malja A, Tahirai D, Zykai R, Bakalis N, et al. Nursing students' attitudes toward statistics: effect of a biostatistics course and association with examination performance. Nurse Educ Today. 2015;35(12):1283-8.

55. Leach MJ, Hofmeyer A, Bobridge A. The impact of research education on student nurse attitude, skill and uptake of evidence-based practice: a descriptive longitudinal survey. J Clin Nurs. 2016;25(1-2):194-203.

56. Lewis $L K$, Wong SC, Wiles LK, McEvoy MP. Diminishing effect sizes with repeated exposure to evidence-based practice training in entry-level health professional students: a longitudinal study. Physiother Can. 2016;68(1):73-80.

57. Liou SR, Cheng CY, Tsai HM, Chang CH. Innovative strategies for teaching nursing research in Taiwan. Nurs Res. 2013;62(5):335-43.

58. Laaksonen C, Paltta H, von Schantz M, Ylönen M, Soini T. Journal club as a method for nurses and nursing students' collaborative learning: a descriptive study. Health Sci J. 2013;7(4):285-92.

59. Malik G, McKenna L, Griffiths D. Using pedagogical approaches to influence evidence-based practice integration - processes and recommendations: findings from a grounded theory study. J Adv Nurs. 2017;73(4):883-93.

60. Mattila L, Rekola L, Koponen L, Eriksson E. Journal club intervention in promoting evidence-based nursing: perceptions of nursing students. Nurse Educ Pract. 2013;13(5):423-8.

61. McCurry MK, Martins DC. Teaching undergraduate nursing research: a comparison of traditional and innovative approaches for success with millennial learners. J Nurs Educ. 2010;49(5):276-9.

62. Milner KA, Cosme S. The PICO game: an innovative strategy for teaching step 1 in evidence-based practice. Worldviews Evid-Based Nurs. 2017;14(6):514-6.

63. Moch SD, Cronje RJ. Part II. Empowering grassroots evidence-based practice: a curricular model to foster undergraduate student-enabled practice change. J Prof Nurs. 2010;26(1):14-22.
64. Moch SD, Cronje RJ, Branson J. Part 1. Undergraduate nursing evidencebased practice education: envisioning the role of students. J Prof Nurs. 2010;26(1):5-13.

65. Morris J. The use of team-based learning in a second year undergraduate pre-registration nursing course on evidence-informed decision making. Nurse Educ Pract. 2016;21:23-8.

66. Morris J, Maynard V. Pilot study to test the use of a mobile device in the clinical setting to access evidence-based practice resources. Worldviews Evid-Based Nurs. 2010;7(4):205-13.

67. Nadelson S, Nadelson LS. Evidence-based practice article reviews using CASP tools: a method for teaching EBP. Worldviews Evid Based Nurs. 2014;11(5):344-6.

68. Nadelson SG. Online resources: fostering students evidence-based practice learning through group critical appraisals. Worldviews Evid-Based Nurs. 2014;11(2):143-4.

69. Niven E, Roy DE, Schaefer BA, Gasquoine SE, Ward FA. Making research real: embedding a longitudinal study in a taught research course for undergraduate nursing students. Nurse Educ Today. 2013;33(1):64-8.

70. O'Neal PV, McClellan LC, Jarosinski JM. A new model in teaching undergraduate research: a collaborative approach and learning cooperatives. Nurse Educ Pract. 2016;18:80-4.

71. Odell E, Barta K. Teaching evidence-based practice: the bachelor of science in nursing essentials at work at the bedside. J Prof Nurs. 2011;27(6):370-7.

72. Oja KJ. Using problem-based learning in the clinical setting to improve nursing students' critical thinking: an evidence review. J Nurs Educ. 2011;50(3):145-51.

73. Pennington K, Moscatel S, Dacar S, Johnson C. EBP partnerships: building bridges between education and practice. Nurs Manag. 2010;41(4):19-23.

74. Phelps SF, Hyde L, Planchon WJ. Introducing information literacy competency standards for nursing. Nurse Educ. 2015:40(6):278-80

75. Phillips RM. Creative classroom strategies for teaching nursing research. Nurse Educ. 2014;39(4):199-201.

76. Pierce LL. The e-poster conference: an online nursing research course learning activity. J Nurs Educ. 2016;55(9):533-5.

77. Putnam J, Faltermeier D, Riggs CJ, Pulcher K, Kitts R. Conquering evidencebased practice using an embedded librarian and online search tool. J Nurs Educ. 2011;50(1):60.

78. Raines DA. A collaborative strategy to bring evidence into practice. Worldviews Evid Based Nurs. 2016;13(3):253-5.

79. Raurell-Torredà M, Romero-Collado À. Simulation-based learning as a tactic for teaching evidence-based practice. Worldviews Evid Based Nurs. 2015;12(6):392-4.

80. Reicherter EA, Gordes KL, Glickman LB, Hakim EW. Creating disseminator champions for evidence-based practice in health professions education: an educational case report. Nurse Educ Today. 2013;33(7):751-6.

81. Revaitis M, Egger S. FaceTime: a virtual pathway between research and practice. Nurse Educ. 2013;38(5):186-7.

82. Roberts D, Ousey K. Finding and using evidence in academic assignments: the bane of student life. Nurse Educ Pract. 2011:11(5):333-40.

83. Rodriguez R. Action research as a strategy for teaching an undergraduate research course. J Nurs Educ. 2012;51(2):102-5.

84. Rolloff M. A constructivist model for teaching evidence-based practice. Nurs Educ Perspect. 2010:31(5):290-3.

85. Ruskjer B. A real-world experience to engage students in evidence-based practice. J Nurs Educ. 2010:49(11):660

86. Ruzafa-Martinez M, Lopez-Iborra L, Armero Barranco D, Ramos-Morcillo AJ. Effectiveness of an evidence-based practice (EBP) course on the EBP competence of undergraduate nursing students: a quasi-experimental study. Nurse Educ Today. 2016;38:82-7.

87. Schams KA, Kuennen JK. Clinical postconference pedagogy: exploring evidence-based practice with millennial-inspired 'building blocks'. Creative Nurs. 2012;18(1):13-6.

88. Schreiner M, Kudrna B, Kenney C. How undergraduate students can contribute to EBP. Nurs Manag. 2015:46(9):21-3.

89. Scott PJ, Altenburger PA, Kean J. A collaborative teaching strategy for enhancing learning of evidence-based clinical decision-making. J Allied Health. 2011:40(3):120-7.

90. Scurlock-Evans L, Upton P, Rouse J, Upton D. To embed or not to embed? A longitudinal study exploring the impact of curriculum design on the evidence-based practice profiles of UK pre-registration nursing students. Nurse Educ Today. 2017;58:12-8. 
91. Sin MK, Bliquez R. Teaching evidence based practice to undergraduate nursing students. J Prof Nurs. 2017;33(6):447-51.

92. Smith-Stoner M. Developing new writers: answering the call for student manuscripts. Dimens Crit Care Nurs. 2011:30(3):160-3.

93. Smith-Strøm H, Oterhals K, Rustad EC, Larsen T. Culture crash regarding nursing students' experience of implementation of EBP in clinical practice. Vard i Norden. 2012;32(4):55-9.

94. Stombaugh A, Sperstad R, Vanwormer A, Jennings E, Kishel H, Vogh B. Using lesson study to integrate information literacy throughout the curriculum. Nurse Educ. 2013;38(4):173-7.

95. Strickland K, Gray C, Hill G. The use of podcasts to enhance researchteaching linkages in undergraduate nursing students. Nurse Educ Pract. 2012;12(4):210-4.

96. Sukkarieh-Haraty O, Hoffart N. Integrating evidence-based practice into a Lebanese nursing baccalaureate program: challenges and successes. Int 」 Nurs Educ Scholarsh. 2017;14(1). https://doi.org/10.1515/ijnes-2017-0026.

97. Whalen KJ, Zentz SE. Teaching systematic searching in a baccalaureate nursing research course. Worldviews Evid-Based Nurs. 2015;12(4):246-8.

98. Wonder AH, Otte JL. Active learning strategies to teach undergraduate nursing statistics: connecting class and clinical to prepare students for evidence-based practice. Worldviews Evid Based Nurs. 2015;12(2):126-7.

99. Yu D, Zhang Y, Xu Y, Wu J, Wang C. Improvement in critical thinking dispositions of undergraduate nursing students through problem-based learning: a crossover-experimental study. J Nurs Educ. 2013;52(10):574-81.

100. Zhang Q, Zeng T, Chen Y, Li X. Assisting undergraduate nursing students to learn evidence-based practice through self-directed learning and workshop strategies during clinical practicum. Nurse Educ Today. 2012;32(5):570-5.

101. Albarqouni L, Hoffmann T, Straus S, Olsen NR, Young T, llic D, et al. Core competencies in evidence-based practice for health professionals: consensus statement based on a systematic review and Delphi survey. JAMA Netw Open. 2018;1(2):e180281.

102. Ahmadi S, Baradaran HR, Ahmadi E. Effectiveness of teaching evidencebased medicine to undergraduate medical students: a BEME systematic review. Med Teach. 2015;37(1):21-30.

103. Albarqouni L, Hoffmann T, Glasziou P. Evidence-based practice educational intervention studies: a systematic review of what is taught and how it is measured. BMC Med Educ. 2018;18(1):177.

104. Tilson JK, Kaplan SL, Harris JL, Hutchinson A, llic D, Niederman R, et al. Sicily statement on classification and development of evidence-based practice learning assessment tools. BMC Med Educ. 2011;11(1):78.

105. Shaneyfelt T, Baum KD, Bell D, Feldstein D, Houston TK, Kaatz S, et al. Instruments for evaluating education in evidence-based practice: a systematic review. JAMA. 2006;296(9):1116-27.

\section{Publisher's Note}

Springer Nature remains neutral with regard to jurisdictional claims in published maps and institutional affiliations.

\section{Ready to submit your research? Choose BMC and benefit from:}

- fast, convenient online submission

- thorough peer review by experienced researchers in your field

- rapid publication on acceptance

- support for research data, including large and complex data types

- gold Open Access which fosters wider collaboration and increased citations

- maximum visibility for your research: over $100 \mathrm{M}$ website views per year

At BMC, research is always in progress.

Learn more biomedcentral.com/submissions 